\title{
Recent Advances in the Synthetic Biology of Natural Drugs
}

\author{
Chun-Qiang Li, Hong-Mei Lei, Qian-Yi Hu, Guo-Hong Li and Pei-Ji Zhao* \\ State Key Laboratory for Conservation and Utilization of Bio-Resources in Yunnan, and Key Laboratory for Microbial \\ Resources of the Ministry of Education, Yunnan University, Kunming, China
}

\section{OPEN ACCESS}

Edited by:

Pablo Carbonell,

Universitat Politècnica de

València, Spain

Reviewed by:

Mario Andrea Marchisio,

Tianjin University, China

Antoine Danchin,

Kodikos Labs Institut Cochin, France

Adam William Westbrook,

Genecis Bioindustries Inc., Canada

*Correspondence:

Pei-Ji Zhao

pjzhao@ynu.edu.cn

Specialty section:

This article was submitted to

Synthetic Biology,

a section of the journal

Frontiers in Bioengineering and

Biotechnology

Received: 05 April 2021

Accepted: 29 June 2021

Published: 29 July 2021

Citation:

Li C-Q, Lei H-M, Hu Q-Y, Li G-H and Zhao P-J (2021) Recent Advances in the Synthetic Biology of Natural Drugs.

Front. Bioeng. Biotechnol. 9:691152.

doi: 10.3389/fbioe.2021.691152
Natural drugs have been transformed and optimized during the long process of evolution. These compounds play a very important role in the protection of human health and treatment of human diseases. Sustainable approaches to the generation of raw materials for pharmaceutical products have been extensively investigated in drug research and development because chemical synthesis is costly and generates pollution. The present review provides an overview of the recent advances in the synthetic biology of natural drugs. Particular attention is paid to the investigations of drugs that may be mass-produced by the pharmaceutical industry after optimization of the corresponding synthetic systems. The present review describes the reconstruction and optimization of biosynthetic pathways for nine drugs, including seven drugs from plant sources and two drugs from microbial sources, suggesting a new strategy for the large-scale preparation of some rare natural plant metabolites and highly bioactive microbial compounds. Some of the suggested synthetic methods remain in a preliminary exploration stage; however, a number of these methods demonstrated considerable application potential. The authors also discuss the advantages and disadvantages of the application of synthetic biology and various expression systems for heterologous expression of natural drugs. Thus, the present review provides a useful perspective for researchers attempting to use synthetic biology to produce natural drugs.

Keywords: natural drugs, synthetic biology, biosynthesis, expression system, optimization

\section{INTRODUCTION}

Natural medicines are natural products with pharmacological activity. Most of these products are compounds produced by secondary metabolism in animals, plants, and microorganisms (Bernardini et al., 2018; Newman and Cragg, 2020). These natural products have been transformed and optimized during the long process of evolution and have good medicinal value (Chevrette et al., 2019; Karunanithi and Zerbe, 2019). These products play very important roles in the protection of human health and in the treatment of human diseases. From 1981 to 2019, 59\% of newly approved small molecule drugs (a total of 1,123) were derived from natural compounds and their derivatives; thus, natural compounds are important resources for modern drug development (Morrison and Hergenrother, 2014; Newman and Cragg, 2020). However, recent demands for drug production and quantity have increased due to increased resistance to pathogenic microorganisms, and traditional methods of the production of natural medicines are unable to meet these demands. The sustainability and green development of production are becoming increasingly prominent needs. Synthetic biology is a new type of modern interdisciplinary life science and systems science that has emerged in the twenty-first century that combines traditional metabolic engineering and concepts 
of systems biology. Recent applications of synthetic biology have provided a strong stimulus to study about natural medicines. Optimized and transformed organisms can continuously and efficiently synthesize specific target compounds with high yield and are characterized by low carbon emissions, environmental friendliness, and cost effectiveness. There is no need to rely solely on traditional discovery and separation or complex synthetic chemistry to obtain a limited number of natural drugs and analogs because new biosynthetic pathways can be designed to produce numerous natural drugs and analogs (Nielsen and Keasling, 2011; Frasch et al., 2013). Development of synthetic biology may bring natural drug research into a new era.

The technology and methods of the synthetic biology of natural products have been extensively reviewed, and basic design principles, routes, and optimization methods have been proposed (Moses et al., 2017; Cravens et al., 2019). The present review describes some studies on natural plant drugs and microbial drugs reported in the past decade and discusses the results of these studies, focusing on the advantages and disadvantages of various heterologous expression systems (Escherichia coli, Bacillus subtilis, yeast, and filamentous fungi). Thus, the present review provides a useful perspective for researchers who plan to use synthetic biology to produce natural drugs.

\section{APPLICATION OF SYNTHETIC BIOLOGY TO PRODUCE NATURAL DRUGS FROM PLANTS}

Currently, plant extraction is a primary method of the production of natural drugs from plants; however, traditional methods of preparation of natural compounds that rely on plant extraction have many limitations. Most natural plant medicines are commonly characterized by extremely low content in the host; for example, $\sim 3 \mathrm{~kg}$ of bark of a 100-year-old Pacific yew may contain only $300 \mathrm{mg}$ of paclitaxel, accounting for $\sim 0.01 \%$ of the dry weight of the bark (Horwitz, 1994). The content of the active ingredient ginsenoside in ginseng aged from 3 to 5 years accounts for only $\sim 2 \%$ of the dry weight of the root, and the content of some rare saponins with important medicinal activities is 0.02-0.0009 wt\% in dried roots (Yoshikawa et al., 1997; Liu, 2012). Traditional plant extraction methods require isolation of trace active ingredients from large quantities of plant resources, which causes considerable waste and serious damage to wild plant resources and may threaten some endangered plant species. Thus, the biosynthesis of natural medicines, such as artemisinin, paclitaxel, tanshinone, breviscapine, noscapine, and thebaine, is used as an example (Figure 1) to apply research advances in synthetic biology to the synthesis of natural plant compounds.

\section{Production of Artemisinin by Combining Synthetic Biology and Synthetic Chemistry}

Malaria is one of the most severe parasitic diseases worldwide. More than 214 million people were infected with malaria in 2015 , leading to 438,000 deaths, primarily among children under 5 years of age. Artemisinin-based combination therapies are currently considered by WHO to be the most effective method for treating malaria (Banek et al., 2014). In 1972, the Chinese scientist $\mathrm{Tu}$ and her team obtained a colorless crystal compound named artemisinin from the plant Artemisia annua (Tu, 2011). However, the content of artemisinin in A. annua accounts for only $0.1-1.0 \%$ of the dry weight of the plant. The production cost of artemisinin is very high due to the unstable structure of artemisinin and complexity of the purification process and hampers the efforts to meet the market demands. Therefore, identification of a more efficient route for the production of artemisinin is urgently needed.

The development of high-throughput sequencing and molecular technology has led to the elucidation of the biosynthetic pathway for artemisinin, and the genes of some key enzymes of the biosynthetic pathway of artemisinin have been cloned and characterized (Lu et al., 2013). The universal 5 -carbon precursors isopentenyl pyrophosphate (IPP) and its double-bond isomer dimethylallyl pyrophosphate (DMAPP) are derived from the mevalonate pathway (MVA) in the cytoplasm of A. annua and from the methylerythritol-4-phosphate pathway (MEP) in plastids (Ma et al., 2015). The artemisinin precursor farnesyl diphosphate (FPP) combines two IPP molecules and a single DMAPP molecule and was shown to be involved in the formation of various isoprenoids (artemisinin, aristolochene, caryophyllene, farnesene, and sterols). The formation of FPP is catalyzed by farnesyl diphosphate synthase (FPS) in artemisinin-producing organisms (Abdin and Alam, 2015). Amorpha-4,11-diene (AD) is the first specific sesquiterpenoid precursor of the artemisinin biosynthesis pathway, formed by cyclization of FPP catalyzed by amorpha-4,11-diene synthase (ADS) (Nguyen et al., 2011). In 2006, the Keasling group (Ro et al., 2006) cloned the amorpha-4,11-diene oxidase gene CYP71AV1 from the glandular hairs of $A$. annua and simultaneously introduced ADS, CYP71AV1, and CPR into Saccharomyces cerevisiae. The yield of artemisinic acid in this yeast cell factory was more than $100 \mathrm{mg} / \mathrm{L}$ (Figure 2, blue route). Artemisinin acid can be efficiently and inexpensively converted to artemisinin by semi-chemical synthesis.

To further improve the yield of artemisinic acid, all genes required for FPP synthesis were overexpressed in $S$. cerevisiae CEN.PK2 (Westfall et al., 2012), including ERG10, ERG13, tHMG1, ERG12, ERG8, ERG19, IDI1, and ERG20, and three copies of $t H M G 1$ were integrated to reach the $40 \mathrm{~g} / \mathrm{L}$ fermentation level of the artemisinin precursor amorpha-4,11diene (Figure 2, pink route). Moreover, the Keasling group (Paddon et al., 2013) combined the expression of ADH1 (the gene encoding NAD alcohol dehydrogenase), ALDH1 (the gene encoding NAD acetaldehyde dehydrogenase), and CYB5 (the cytochrome b5 gene) to produce the highest concentration of artemisinic acid (25 g/L; Figure 2, purple route). In the final steps of artemisinin biosynthesis, it is still unclear whether the conversion from dihydroartemisinic acid to artemisinin is enzymatic or nonenzymatic in $A$. annua. It is known that dihydroartemisinic acid could be converted to artemisinin in a non-enzymatic manner through spontaneous autoxidation (Sy and Brown, 2002). However, it is not clear whether a series of similar spontaneous oxidations occurs in plants, or whether 


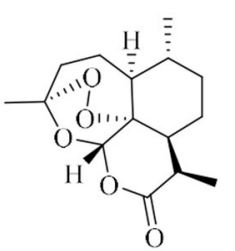

artemisinin<smiles>Cc1coc2c1C(=O)C(=O)c1c-2ccc2c1CCCC2(C)C</smiles>

tanshinone IIA

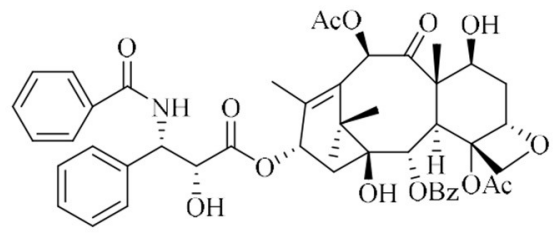

paclitaxel<smiles>O=C(O)C1OC(Oc2cc(O)c3c(=O)cc(-c4ccc(O)cc4)oc3c2)C(O)C(O)C1O</smiles>

breviscapine

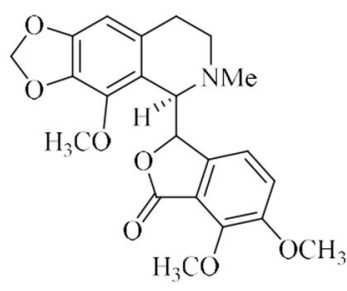

noscapine

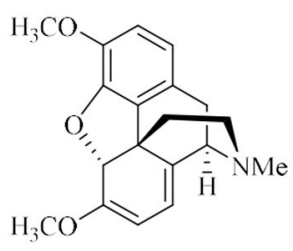

thebaine<smiles>COc1cc([C@H]2c3cc4c(cc3[C@@H](CC3O[C@@H]5CO[C@H](C)O[C@H]5[C@H](O)[C@H]3O)[C@H]3COC(=O)[C@H]23)OCO4)cc(OC)c1O</smiles>

etoposide

FIGURE 1 | Some natural drugs studied by synthetic biology.

there are enzymes to catalyze certain steps in this pathway in vivo (Brown and Sy, 2004; Bryant et al., 2015). In general, many biosynthetic pathways in A. annua competes with the artemisinin biosynthetic pathway for metabolic flux; therefore, RNA interference technology is used to introduce antisense strands of cDNA into $A$. annua to downregulate the expression levels of $\beta$-farnesyl pyrophosphate synthase, $\beta$-caryophyllene synthase (CPS), and squalene synthase to block the effects of the pathways that compete with artemisinin biosynthesis ( $\mathrm{Lv}$ et al., 2016). The yield of artemisinin in all transgenic plants of $A$. annua increased by $\sim 70 \%$ compared with that obtained from the control plants. In addition, organism is a complex membrane structure system; compartmentalization of secondary metabolite biosynthetic process not only allows enzymes to be aggregated as functional units, but also separates the pathway from the rest of the cell. Co-compartmentalization of biosynthetic enzymes can be expected to allow certain types of selective advantages. The colocalization of continuous enzymes in the secondary metabolite biosynthetic pathway can promote pathway efficiency through proximity. This is especially important if the products and intermediates may be toxic to the production cell (Roze et al., 2011; Kistler and Broz, 2015). In A. annua, artemisinin biosynthesis is localized in the two outer apical cells of the glandular trichomes, which are specialized structures, found mainly on the surface of leaves and flowers (Olsson et al., 2009). Furthermore, oxidation reactions of dihydroartemisinic acid are also believed to occur in the glandular trichomes (Brown, 2010). But how this special structure plays a role in oxidation catalysis is still unclear. In 2016, the Fuentes team (Fuentes et al., 2016) developed a method of combinatorial super transformation of chloroplast-transformed recipient lines (COSTREL), which constructed large transformation vectors expressing multiple pathway genes, and inserted them into chloroplast genomes. They screened many transgenic lines by their physiological and phenotypic changes. This strategy transferred the entire biochemical metabolic pathway from a medicinal plant to a high-biomass crop, and $120 \mathrm{mg}$ of artemisinic acid was isolated per kilogram of transgenic tobacco. A complete pathway of artemisinin synthesis was achieved in tobacco by coexpressing five genes [HMGR, ADS, CYP71AV1, CPR, and DBR2 (the gene encoding artemisinic aldehyde double bond reductase)] and the artemisinin content reached $6.8 \mu \mathrm{g} / \mathrm{g}$ dry weight (Farhi et al., 2011a). Through further optimization of metabolic pathways and using cellular compartments, the yield of artemisinin in tobacco was increased to $0.8 \mathrm{mg} / \mathrm{g}$ dry weight (Malhotra et al., 2016). This yield is much lower than the content of artemisinin in A. annua, but it is an important achievement. In general, metabolic optimization can increase the content of target compounds, but how cellular compartments work is unclear. A specific lipid transfer protein from A. annua can boot transient production of artemisinin in tobacco (Wang et al., 2016). This result further suggested that compartment plays an important role in artemisinin biosynthesis (Ikram et al., 2017) because the function of transporters is to transport specific molecules to particular areas in vivo. In plants the metabolic networks are compartmentalized, and biochemical steps of a single pathway can occur in multiple subcellular locations. Due to the results of tracking the distribution of proteins and metabolites in the various compartments, we have a certain understanding of the reactions and precursor compounds in 


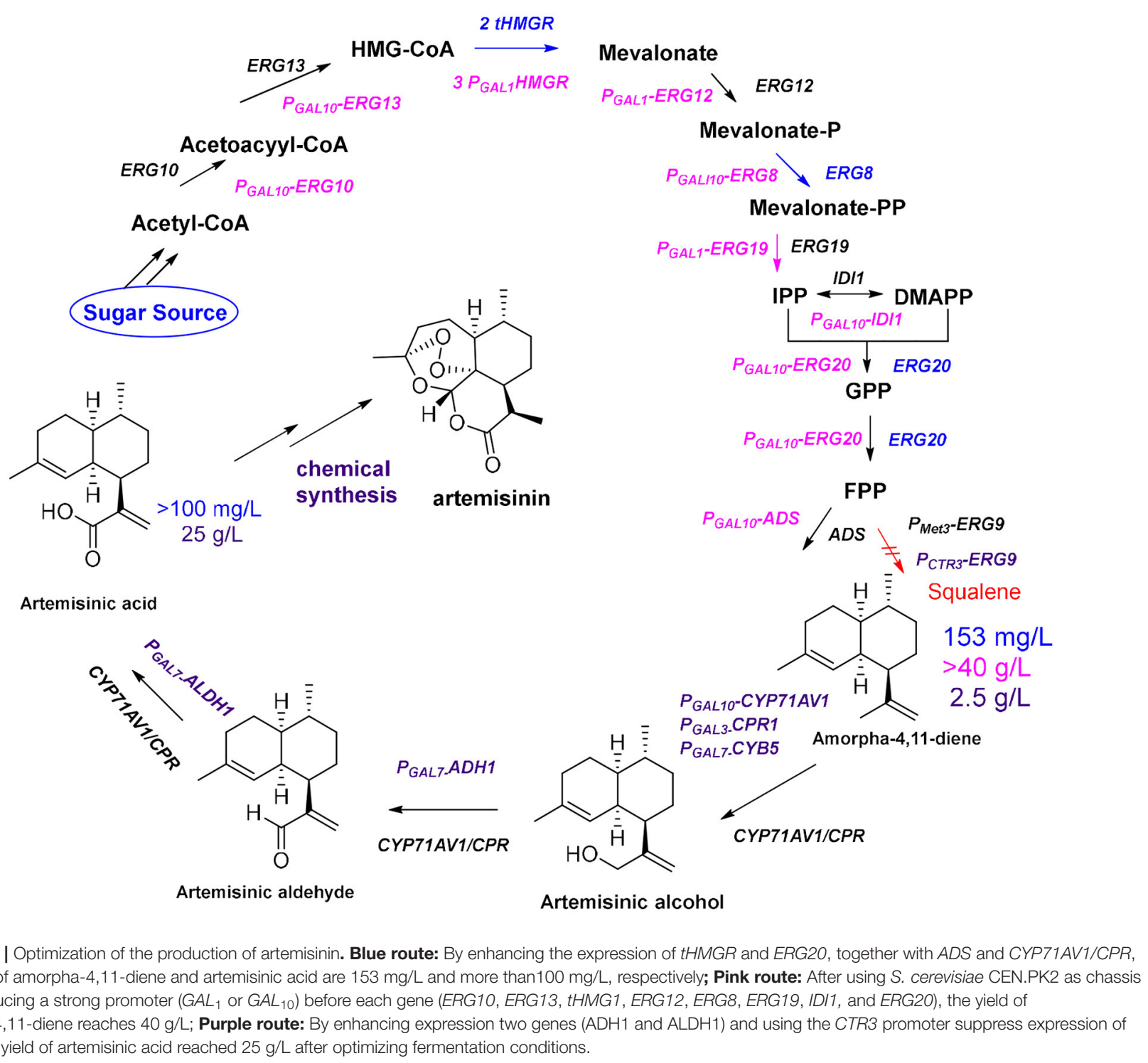

various compartments (Heinig et al., 2013). Up to now, the main source of artemisinin on the market is still the extract from $A$. annua. An alternative approach would be to try to reconstruct the microbial fermentation process by mimicking the process that occurs under natural conditions. This requires us to deeply understand the functions and mechanisms of specific compartments in metabolic networks. For example, how dihydroartemisinic acid is oxidized to artemisinin in glandular trichomes, which requires more fundamental research. But the ultimate reward will be the production of artemisinin through a single fermentation process.

\section{Production of the Paclitaxel Precursors by Pathway Optimization}

Paclitaxel is a diterpenoid anticancer drug isolated from Chinese yew (Taxus chinensis) and is the first-line drug for the clinical treatment of ovarian cancer and breast cancer (Zhang, 2014). The content of paclitaxel in yew is very low, and the resources of $T$. chinensis are scarce. The route of total chemical synthesis of paclitaxel is complex and costly; therefore, semichemical synthesis is an important method for the industrial production of paclitaxel ( $\mathrm{Li}$ et al., 2015). The basic biosynthetic route of paclitaxel has been determined, and most of the enzymes have been obtained and functionally identified. Currently, 14 of the 19 enzymes required for the biosynthetic pathway of paclitaxel have been identified; however, the order in which most of these enzymes, especially P450 enzymes, participate in the pathway has not yet been determined (Jennewein and Croteau, 2001; Schoendorf et al., 2001; Jennewein et al., 2005; Koeksal et al., 2011; Wang et al., 2018).

Microbial synthesis of paclitaxel precursors and semisynthesis of paclitaxel are currently the most promising methods for the 
production of this drug, and these methods are expected to solve the problems of high price and short supply of paclitaxel in the market. It is also very important to protect endangered $T$. chinensis (Liu et al., 2016). A brief biosynthetic pathway involves the cyclization of GGPP to taxa-4(5),11(12) diene by taxadiene synthase (Koeksal et al., 2011); hydroxylation of taxane skeleton at $\mathrm{C} 5, \mathrm{C} 10, \mathrm{C} 13, \mathrm{C} 2, \mathrm{C} 9, \mathrm{C} 7$, and $\mathrm{C} 1$ by cytochrome P450 monooxygenase to form oxetane; the formation of epoxypropane D-ring at $\mathrm{C} 4$ and $\mathrm{C} 5$; and then $\mathrm{CoA}$ acylation to synthesize the key intermediate baccatin III (Croteau et al., 2006). The C13 side chain of taxol is the key group for anticancer activities. Baccatin III is connected with phenylisoserine side chain at C13, and then hydroxylated and benzoylated at C2 and C3 of the side chain to achieve paclitaxel (Howat et al., 2014). Jennewein and coworkers simultaneously overexpressed four genes in S. cerevisiae (Engels et al., 2008), including the genes encoding taxadiene synthase, geranylgeranyl diphosphate (GGPP) synthase, HMG1 reductase (thmgr), and the transcription factor UPC2-1. The yield of taxa4(5),11(12)-diene in the engineered microorganism was $8.7 \pm$ $0.85 \mathrm{mg} / \mathrm{L}$, and geranylgeraniol accumulated at concentrations of up to $33.1 \pm 5.6 \mathrm{mg} / \mathrm{L}$ (Figure 3, blue route). The Scott team introduced four genes (1-deoxy-D-xylulose 5-phosphate (DXP) synthase, IDP isomerase, GGDP synthase, and taxadiene synthase) to engineer $E$. coli to produce taxadiene for the first time; the authors confirmed that DXP reductoisomerase catalyzes the conversion of DXP to C-methyl-4-erythritol-4-phosphate (Huang et al., 2001). Then, the synthetic genes were divided into an upstream module ( $d x s$-idi-ispD-ispF, containing genes responsible for IPP and DMAPP synthesis) and a downstream module (containing genes responsible for GGPP and taxadiene synthesis). Four genes (dxs-idi-ispD-ispF) of the upstream metabolic module were overexpressed by an operon, and the expression of the two genes of the downstream module was regulated by changing the plasmid copy number and the strength of the promoter. Thus, a taxa-4(5),11(12)-diene yield of 1.02 $\pm 0.08 \mathrm{~g} / \mathrm{L}$ in E. coli (Figure 3, pink route), which was a breakthrough in paclitaxel synthesis, was achieved by synthetic biology (Ajikumar et al., 2010). P450-mediated oxidation is the vital reaction for taxadiene to synthesize baccatin III; thus, two P450 enzymes and an acetyltransferase enzyme were introduced into yeast; subsequent coculture of this yeast and $E$. coli was used to obtain taxadien- $5 \alpha$-acetate- $10 \beta$-ol yield of $1 \mathrm{mg} / \mathrm{L}$ (Figure 3, purple route; Zhou et al., 2015). Low expression and weak catalytic activity of CYPs involved in modification of the taxadiene skeleton are the major stumbling block to further construct the production taxadiene- $5 \alpha-$ ol in yeast and E. coli. There are often many P450 enzymes involved in the biosynthesis of metabolites (Gnanasekaran et al., 2016), and P450 enzymes of most eukaryotes are membrane bound. Therefore, in the process of constructing and engineering strains full consideration of membrane structure and compartmentalization may be an important aspect to increase yield (Bharati et al., 2012). Wang team employed a compartmentalized metabolic engineering strategy and introduced the genes of taxadiene synthase, taxadiene-5 $\alpha$-hydroxylase, and cytochrome $\mathrm{P} 450$ reductase in the chloroplasts of Nicotiana benthamiana for the production of taxadiene- $5 \alpha$-ol in tobacco leaves with $1.3 \mu \mathrm{g} / \mathrm{g}$ of fresh weight
(Li et al., 2019). Expedient identification of the catalytic elements required for the formation of the $\mathrm{D}$ ring and carbonylation of the C-9 position during the synthesis of baccatin III is expected to enable the biosynthesis of 10-desacetylbaccatin III and subsequent chemical synthesis of docetaxel. So far, the epoxidase and oxomutase related to the synthesis of baccatin III have not been cloned and identified. Therefore, for paclitaxel, the first thing to be solved is to elucidate the unclear reactions and the functions of those enzymes in the biosynthetic pathway. In further reconstruction of the biosynthetic pathway, due to the large number of oxidation reactions in the postmodification process, it is an essential and important factor to fully consider the compartmentalized strategy (Du and Li, 2021).

\section{Assembly of the Precursors of Tanshinone and Breviscapine}

Salvia miltiorrhiza Bunge (Danshen) is a medicinal plant of the Lamiaceae family. Dried roots of this plant have been used in TCM for a long time because the hydrophilic phenolic acids and lipophilic constituents of these roots are pharmaceutically active components (Wu and Wang, 2012; Xu et al., 2018). Most of the lipophilic constituents, tanshinone I (TS I), TS IIA, and cryptotanshinone (CTS), have multiple pharmacological activities, including anticancer (Kim et al., 2015; Munagala et al., 2015) and antibacterial effects (Yu et al., 2014), and can be efficiently used for the treatment of cardiovascular diseases ( $\mathrm{Wu}$ and Wang, 2012; Xu et al., 2018). GGPP is the tanshinone precursor in the cytosolic MVA pathway and plastid-localized MEP pathway and is cyclized by the enzymes diterpene synthase copalyl diphosphate synthase (SmCPS) and kaurene synthaselike (SmKSL) to form the diterpenoid skeleton of miltiradiene (Zhou et al., 2012), which is an important precursor for the biosynthesis of tanshinone.

Using the modularized pathway engineering techniques, a mutigenes cassette encoding SMCPS, SMKSL, ERG-20, BTS1, and HMG1 was established, and a high yield of miltiradiene (365 mg/L) was obtained in yeast (Zhou et al., 2012). Optimization of the pathway in a yeast expression system (Dai et al., 2012) achieved a miltiradiene yield of $488 \mathrm{mg} / \mathrm{L}$ (Figure 4, purple route). By knocking out UAS to repress the expression of ERG9, knocking out Rox1 (repressor of hypoxia) transcriptional regulator, and deleting the distant genetic loci YPL062w and YJL064w, a high-yielding GGPP chassis line was obtained; then, two high-efficiency catalytic enzymes (CfTPS1 and SmKSL1) were constructed to be a SmKSL1-CfTPS1 fusion protein, which can convert GGPP to milradiradiene with the highest efficiency in yeast; finally, the production of milradiradiene was further increased by truncating the N-terminal chloroplast transit peptide (M1-C47) of SmKSL1, and the yield of miltiradiene was increased to $3.5 \mathrm{~g} / \mathrm{L}(\mathrm{Hu}$ et al., 2020). Moreover, some cytochrome P450 monooxygenases (CYP76AH1, CYP76AH3, and CYP76AK1) were identified and functionally characterized to participate in the conversion of miltiradiene to 11,20-dihydroxy ferruginol (Guo et al., 2013, 2016). The subsequent oxidation-reduction steps of the downstream pathway of biosynthesis of tanshinone from 


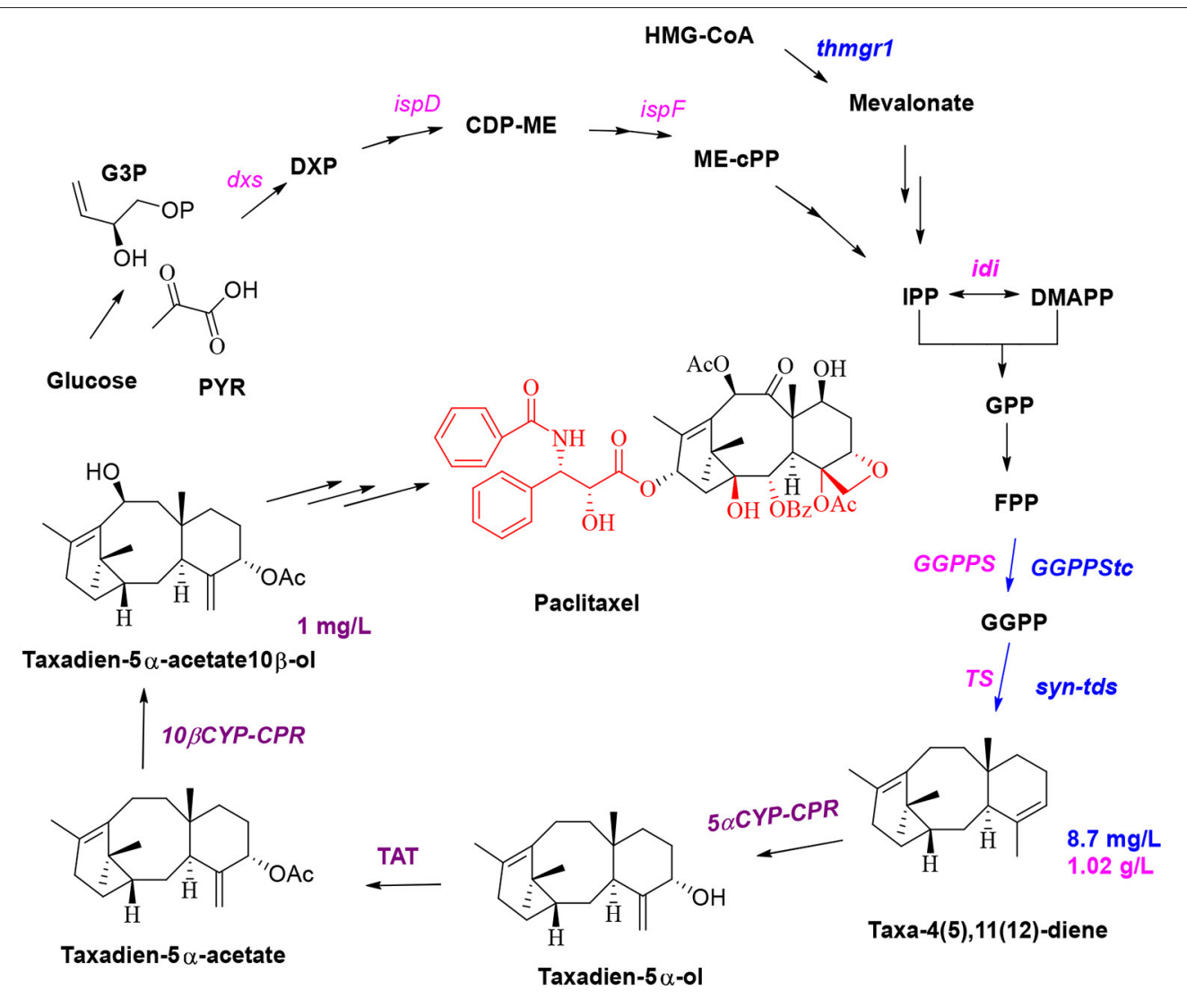

FIGURE 3 | Optimization of the production of the paclitaxel precursors.

11,20-dihydroxy ferruginol are unclear (Figure 4). Moreover, the conversion of miltiradiene to tanshinone requires multioxidation reactions by CYPs (Mizutani and Sato, 2011; Xu et al., 2015). Through transcriptome data, four potential CYP450s may involve in tanshinone biosynthesis compared with the methyl jasmonate induction group (Chang et al., 2019). However, it requires a lot of hard work to identify and elucidate the functions of CYPs in tanshinone biosynthesis.

Breviscapine is a traditional Chinese medicine (TCM) prescription drug obtained from Erigeron breviscapus and is used for the treatment of cardio- and cerebrovascular diseases (Gao et al., 2017), which are the main causes of death and disability worldwide (Prince et al., 2015). A gradual increase in the aging population of China has resulted in the growing market demand for breviscapine, and the extraction of E. breviscapus is insufficient to meet these needs. Thus, identification of new methods to obtain high amounts of breviscapine is urgently required. Scutellarin and 7-O-glucuronide apigenin are the two main precursors of breviscapine; these compounds are generated by glycosylation of apigenin and scutellarein at C-7 (Jiang et al., 2014). The catalysis steps from L-phenylalanine to apigenin were characterized and include six enzymes, namely: phenylalanine ammonia-lyase (PAL), cinnamate-4-hydroxylase, 4-coumaroyl-CoA ligase (4CL), chalcone synthase, chalcone isomerase, and flavone synthase II (Pandey et al., 2016). In
2018, two key genes, namely, F7GAT (encoding flavonoid-7-Oglucuronosyltransferase, which converts apigenin into apigenin7-O-glucuronide) and $\mathrm{F} 6 \mathrm{H}$ (encoding flavone-6-hydroxylase, which catalyzes C-6 hydroxylation of apigenin and apigenin7-O-glucuronide), were characterized and engineered to be expressed in combination with the six genes described above in yeast to establish a microbial factory. The yields of scutellarin and apigenin-7-O-glucuronide in yeast factories reached 108 and $185 \mathrm{mg} / \mathrm{L}$, respectively (Liu et al., 2018). Scutellarin is the main active component for clinical usage in E. breviscapus (Chledzik et al., 2018). Although in the present work, a considerable yield was achieved, but it was not sufficient for commercial production. It requires to further optimize the metabolic pathway, especially enhancing expression of two genes (encoding PAL and 4CL), which may be the limiting steps in flavonoid biosynthesis (Stahlhut et al., 2015; Nabavi et al., 2020).

\section{Formation of Two Benzylisoquinoline Alkaloids}

Analgesic morphine and antitussive codeine are important medicines for pain management and palliative care. Thebaine is the key benzylisoquinoline alkaloid in the biosynthesis of opium poppy (Papaver somniferum) and an important starting material for the semisynthesis of widely demanded drugs (oxycodone, naltrexone, and naloxone) 


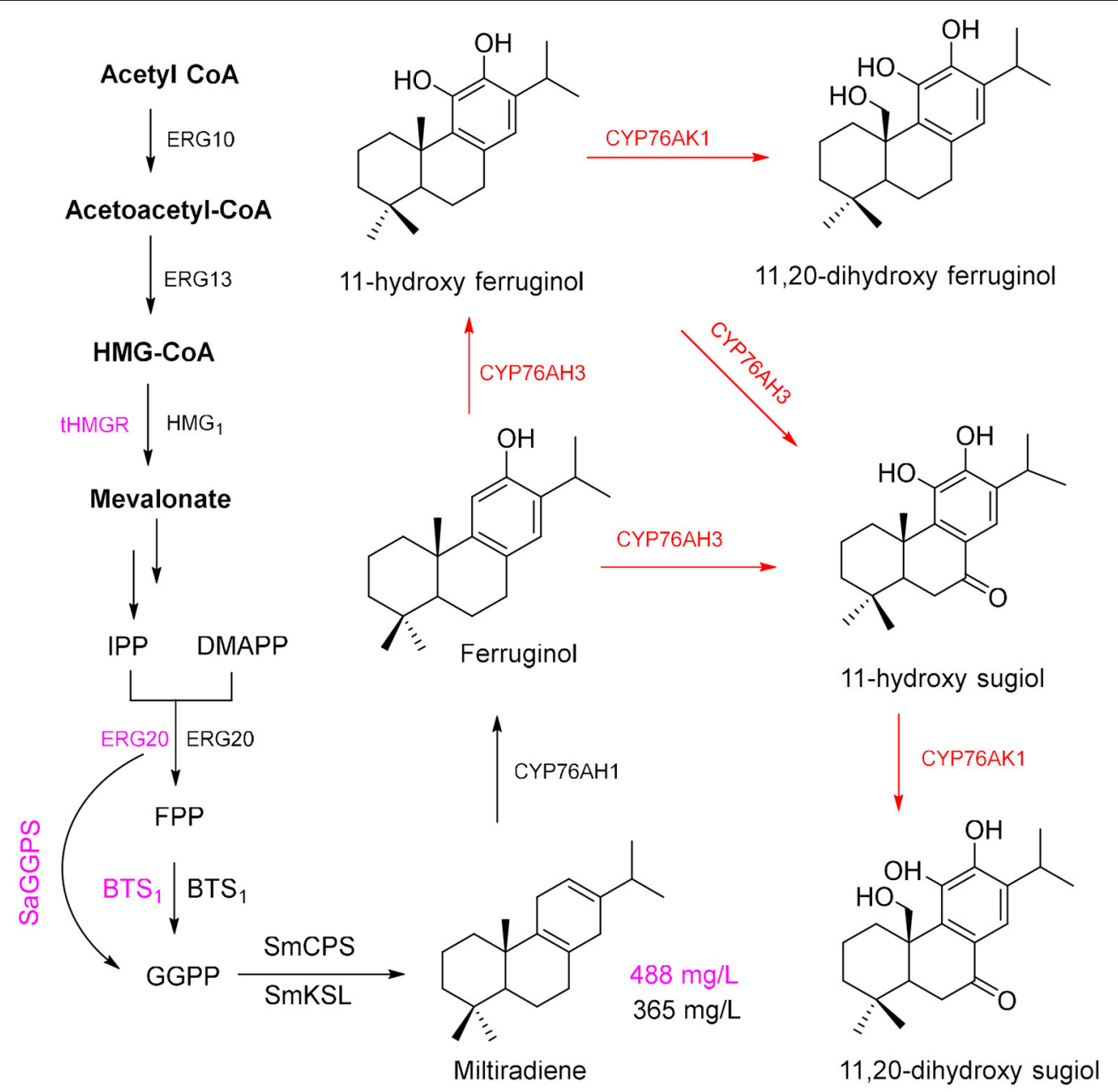

FIGURE 4 | Production route for tanshinone precursors.

(Ehrenworth and Peralta-Yahya, 2017; Presley and Lindsley, 2018). Recent efforts to reconstitute the production of opiate alkaloids in microbial systems by genetic engineering are expected to alleviate market concerns surrounding plant-based production, including the adverse effects of climate change, pests, and diseases (Tatsis and O'Connor, 2016). Thebaine biosynthesis is complex, and the route starts from 4-hydroxyphenylacetaldehyde (4-HPAA) and dopamine to generate the primary intermediate (S)-norcoclaurine by norcoclaurine synthase (NCS); then, (S)-norcoclaurine is converted to (S)reticuline via a series of reactions catalyzed by norcoclaurine 6-O-methyltransferase (6OMT), coclaurine $\mathrm{N}$-methyltransferase (CNMT), and 4'-O-methyltransferase (4OMT). Then, a critical step of the conversion of $(S)$-reticuline to $(R)$-reticuline is catalyzed by 1,2-dehydroreticuline synthase (DRS) and 1,2dehydroreticuline reductase (DRR). Salutaridine, the first tetracyclic promorphinian alkaloid, is formed via intramolecular carbon-carbon phenol coupling of $(R)$-reticuline catalyzed by the cytochrome P450 monooxygenase salutaridine synthase (SalSyn). NADPH-dependent salutaridine reductase (SalR) reduces the $\mathrm{C} 7$ keto group of salutaridine in a stereospecific manner, yielding salutaridinol, which undergoes stoichiometric transfer of an acetyl group to the C7 hydroxyl moiety by acetylCoA-dependent salutaridinol 7-O-acetyltransferase (SalAT) to form salutaridinol-7-O-acetate. Spontaneous loss of the acetyl group results in rearrangement to thebaine, the first pentacyclic morphinian alkaloid. Thebaine is O-demethylated by thebaine 6O-demethylase (T6ODM) to neopinone, which is spontaneously converted to codeinone (Hirata et al., 2004; Ziegler et al., 2009; Onoyovwe et al., 2013).

In 2015, the Galanie team reported their landmark work in yeast to achieve the biosynthesis of opioid compounds (thebaine and hydrocodone) from glucose (Galanie et al., 2015). Successful construction of a thebaine synthesis pathway containing 21 enzymes and a hydrocodone synthesis pathway containing 23 enzymes in yeast involved 24 heterologous expression cassettes, including 21 exogenous enzymes from plants, mammals, and bacteria. Overexpression of two native yeast enzymes and inactivation of a native yeast enzyme resulted in the final titer of thebaine reaching $6.4 \pm 0.3 \mu \mathrm{g} / \mathrm{L}$ (Figure 5). The final step 

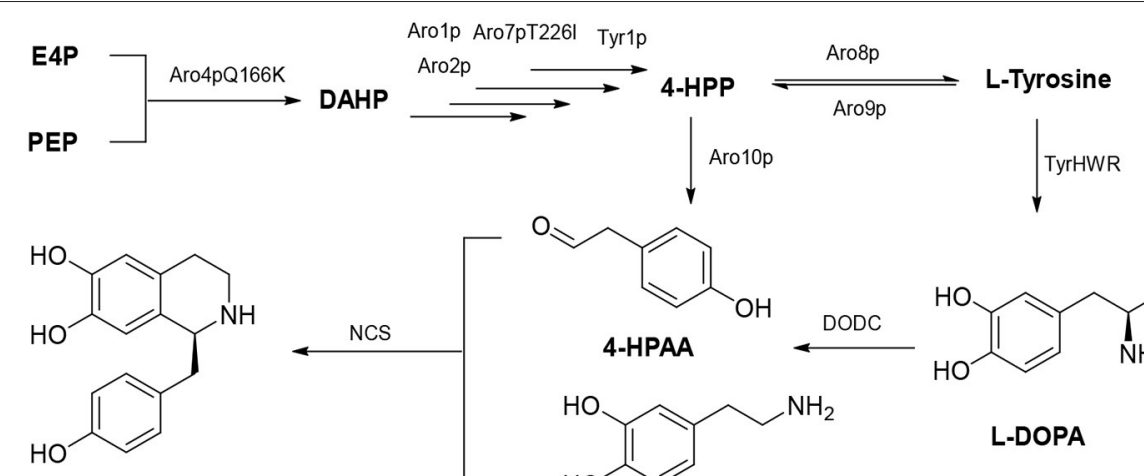

(S)-Norcoclaurine
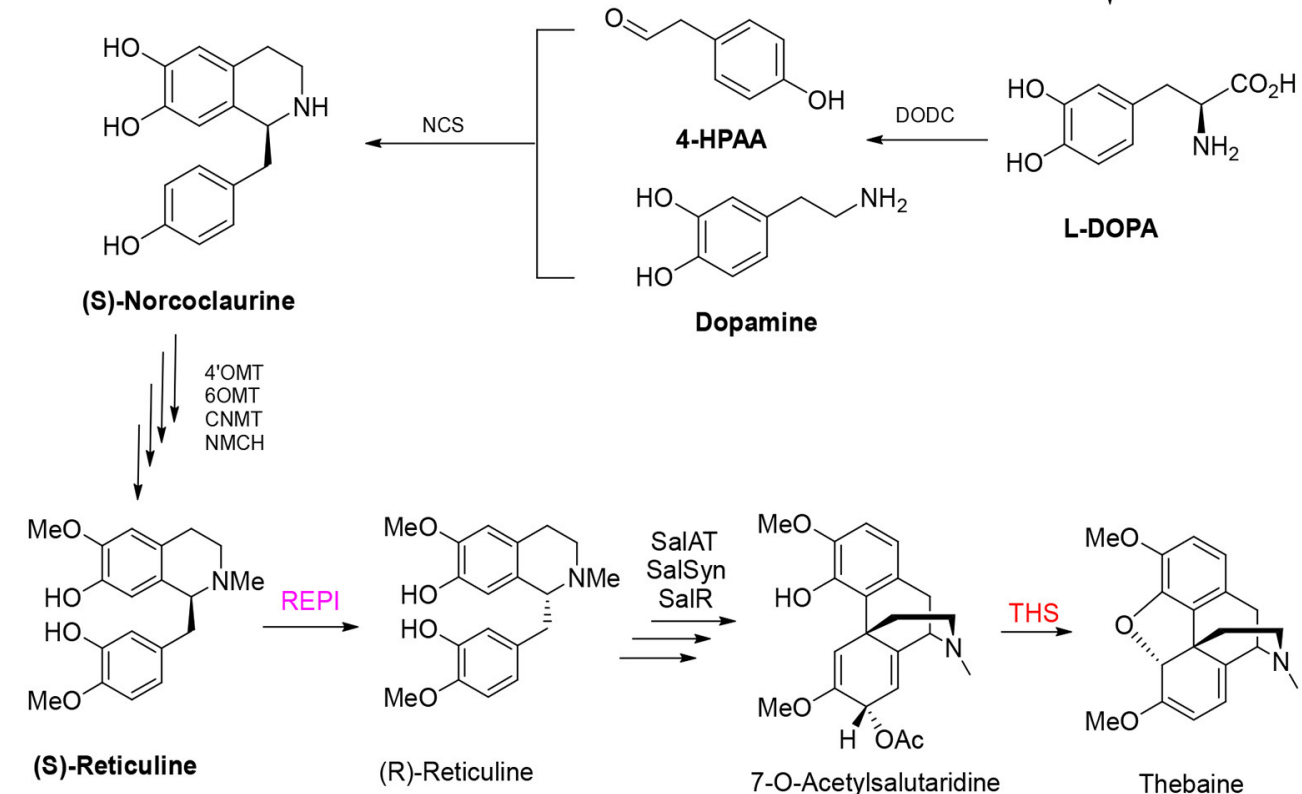

Dopamine
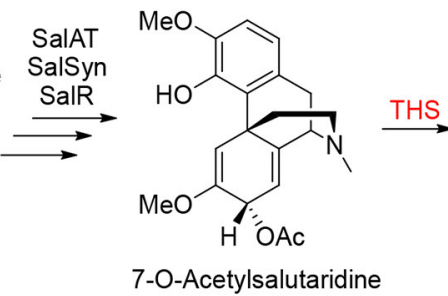

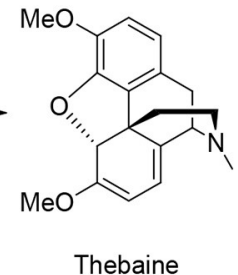

FIGURE 5 | Production of thebaine in engineered yeast.

in the formation of thebaine has been considered a spontaneous reaction for considerable time (Lenz and Zenk, 1995). However, thebaine synthase (THS) was shown to produce thebaine by the efficient hydroxylation of (7S)-salutaridinol-7-O-acetate, and introduction of the enzyme into engineered yeast increased the yield of thebaine 20-fold (Chen et al., 2018).

Noscapine is another benzylisoquinoline alkaloid (BIA) used as an antitussive drug (Rida et al., 2015); unlike opiate alkaloids, noscapine does not possess analgesic or narcotic properties. All noscapinoids have been isolated from opium poppy, seriously restricting the application of noscapine in the pharmaceutical market due to the negative environmental effects and high cost of large-scale synthesis of noscapine (Chen et al., 2015). The biosynthetic route of noscapine involves 11 enzymatic steps, starting from the key intermediate $(S)$-reticuline, which is a BIA branch-point precursor for the formation of noscapine and morphine (Dang and Facchini, 2012). In 2012, a 10gene cluster encoding enzymes responsible for the biosynthesis of noscapine from $(S)$-scoulerine was identified in opium poppy (Winzer et al., 2012). The cluster encodes four cytochrome P450 monooxygenases (CYP719A21, CYP82Y1, CYP82X1, and CYP82X2), three methyltransferases (PsMT1, PsMT2, and PsMT3), a carboxylesterase (PsCXE1), a short-chain dehydrogenase/reductase (PSSDR1), and an acetyl transferase (PsAT1), making it one of the most complex natural product pathways described in plants. In 2016, Li et al. engineered a gene cluster in yeast for the production of noscapine, with a yield of $1.64 \pm 0.38 \mu \mathrm{M}$, starting from the simple alkaloid norlaudanosoline and utilizing 14 biosynthetic steps (Li et al., 2016). This experiment validated the reaction matrix of the final three steps (PsCXE1, PsSDR1, and PsMT2/PsMT3) and suggested that the remaining 4-O-methylation step is catalyzed by two different $\mathrm{O}$-methyltransferases together. Furthermore, this research team combined and introduced more than 30 enzymes from plants, bacteria, mammals, and yeast into chassis cells for efficient synthesis of (S)-reticuline, including 7 endoplasmic reticulum (ER)-localized plant enzymes, by de novo production of noscapine in S. cerevisiae (Li et al., 2018). Modification and optimization of norcoclaurine synthase and tyrosine hydroxylase increased the content of noscapine 18,000-fold to reach the yield of $2.2 \mathrm{mg} / \mathrm{L}$. Even though this yield of noscapine did not result in commercial production by microorganisms, the microbial biosynthetic platform is expected to promote the discovery and development of alkaloid drugs.

The opium poppy, $P$. somniferum, is the source of codeine and morphine, which accumulate in special cells called laticifers. Morphine, codeine, and thebaine exist in roots and aerial plant parts, and especially accumulate in vesicles in laticifers (Weid et al., 2004; Beaudoin and Facchini, 2014). Several enzymes involved in the biosynthesis of benzylisoquinoline alkaloids are related to subcellular compartments other than the cytosol. For instance, NCS, BBE, and DBOX are presumably located in the lumen of the endoplasmic reticulum (ER); and cytochrome P450 enzymes ( $\mathrm{NMCH}, \mathrm{CFS}$, SPS $\mathrm{MSH}$, and $\mathrm{P} 6 \mathrm{H}$ ) are anchored in the cytoplasmic side of the ER, while methyltransferases (6OMT, CNMT, 4'OMT, and TNMT) are contained in the cytosol 
(Beaudoin and Facchini, 2014; Singh et al., 2019). Subcellular compartmentalization is an evolutionary strategy for dealing with unproductive or harmful crosstalk. In eukaryotes, organelles enclosed by lipid membranes are used to direct enzyme activity to specific substrates. Several benzylisoquinoline alkaloids (e.g., thebaine, noscapine, sanguinarine, and dihydrosanguinarine) were rebuilt the full biosynthetic pathways into microorganisms (Fossati et al., 2014; Trenchard and Smolke, 2015). However, the low yield is far from reaching the expected purpose of using microbial fermentation to produce. Toxicity of heterologous proteins and metabolites is a crucial problem in using synthetic biology to produce natural drugs. The toxicity will lead to slow growth of the host and low content of the final target compound in the fermentation production process. When producing benzylisoquinoline alkaloid by heterologous expression in $S$. cerevisiae, the enzyme NCS that synthesizes $(S)$-norcoclaurine was toxic in the cytosol of host. But high production of benzylisoquinoline alkaloid in heterologous hosts required high NCS activity. The team of Dueber utilized compartmentalization of toxic NCS in the peroxisome, and this alleviates cytotoxicity, thereby increasing the production of benzylisoquinoline alkaloid (Grewal et al., 2021). Therefore, after the complete biosynthetic pathways are characterized at the biochemical and genetic levels, the understanding of enzyme interaction, metabolic regulation, and compartmentalization will be more important challenges for commercial production.

\section{Biosynthesis of Etoposide}

Etoposide is a plant-derived drug and is used in chemotherapy regimens for the treatment of lung cancer, testicular cancer, lymphomas, and other malignancies (Hande, 1998). Etoposide is synthesized starting from two coniferyl alcohols that form pinoresinol in a reaction catalyzed by dirigent protein oxidase (DPO). Pinoresinol is reduced through lariciresinol to form secoisolariciresinol by pinoresinol-lariciresinol reductase (PLR), and this product is subsequently oxidized to matairesinol by secoisolariciresinol dehydrogenase (SDH); then, matairesinol is converted to pluviatolide in a methylenedioxy bridge formation reaction catalyzed by CYP719A23 and CYP719A24 (Marques et al., 2013; Teponno et al., 2016). In 2015, Lau and Sattely (2015) used transcriptome mining in Podophyllum hexandrum (mayapple) to identify biosynthetic genes of the podophyllotoxin pathway. The expression of 29-candidate gene combinations in tobacco was used to identify six enzymes (OMT3, CYP71CU1, OMT1, 2-ODD, CYP71BE54, and CYP82D61) required for complete biosynthesis of etoposide aglycone. By coexpression of 10 genes in tobacco, they reconstituted the pathway to (-)-4' desmethylepipodophyllotoxin (the etoposide aglycone), which is a more direct precursor of etoposide than (-)-podophyllotoxin. At present, the biosynthetic pathway for the production of etoposide aglycone (EA) can be divided into three parts as follows: the pathway of endogenous secondary tobacco metabolite coniferyl alcohol (CA), the pathway from CA to (-)-deoxypodophyllotoxin (DPT), and the pathway from DPT to EA. The products at these levels can be readily distinguished by mass spectrometry; however, a considerable increase in production will be required for facile isolation of pure DPT and other late-stage intermediates. Lau hypothesized that catalyzing $\mathrm{CA}$ to (+)-pinoresinol is the limiting step in the biosynthetic process of DPT as the DPT yield increases eight times after adding (+)-pinoresinol to the plant chassis as a precursor (Lau and Sattely, 2015). Eight genes (PAL, C4H, 4CL, HCL, C3H, CCoA-OMT, CCR, and CAD) that enable CA production from intracellular phenylalanine and eight other genes (DIR, PLR, SDH, CYP719A13, OMT3, CYP71CU1, OMT1, and 2ODD) that enable the generation of DPT from CA were coexpressed in tobacco leaves to improve the DPT yield in the tobacco system. The accumulation of DPT reached $4.3 \mathrm{mg} / \mathrm{g}$ of dry plant weight (Schultz et al., 2019). Ten percent of essential medicines, as defined by WHO, are derived from natural plant products, a majority of which rely on native plants for production (Davey, 2020). Therefore, it is alternate to use tobacco as a production platform for natural products of medicinal plants. From some successful examples of mass production of target products, rebuilding the biosynthetic pathway of target molecules in microbial chassis cells is an important foundation; subsequently, the optimization of metabolic pathway and search for highefficiency catalytic enzymes are essential.

\section{APPLICATION OF SYNTHETIC BIOLOGY FOR MICROBIAL DRUGS}

Microbial drugs have become the main rich source of natural drugs due to their novel structures, diverse activities, and short production cycles. More than $70 \%$ of antiinfection drugs and $50 \%$ of drugs for tumor chemotherapy used in the clinic are directly or indirectly derived from microorganisms (Newman and Cragg, 2012). Microorganisms can produce more target metabolites than plants; however, optimization and rearrangement of biosynthetic gene clusters to form a novel route is required for some target metabolites whose yield cannot be increased in the original strain.

\section{Heterologous Expression of Epothilone}

Epothilone is a macrolide produced by the mycobacterium Sorangium cellulosum and has antibacterial and cytotoxic activities (Castro-Alvarez et al., 2018). Epothilone and paclitaxel have similar antitumor mechanisms, and epothilone showed several advantageous characteristics, such as simple structure, increased water solubility, and better anticancer activity compared with those of paclitaxel. Thus, epothilone is widely regarded as a potential antitumor drug (Thomas et al., 2007; Sparano et al., 2010). Epothilone is produced as a secondary metabolite in bacteria; however, its yield is very low due to difficulties in the genetic manipulation of S. cellulosum, which greatly limits the application of epothilone in cancer treatment.

In 2000, a 56-kb gene cluster responsible for epothilone biosynthesis was identified; the cluster consists of a loading module, a non-ribosomal peptide synthase module, eight polyketide synthase modules, and a P450 cyclooxygenase enzyme (Gerth et al., 2000; Tang et al., 2000). The Julien team introduced the genes encoding these enzymes into Streptomyces coelicolor to achieve heterologous production of epothilones A and B for the first time (Tang et al., 2000). The gene cluster encoding the 
NRPS/PKS enzyme complex, which catalyzes the biosynthesis of epothilones $\mathrm{C}$ and $\mathrm{D}$, consists of six open reading frames (ORFs), namely: epoA, epoB, epoC, epoD, epoE, and epoF. Mutka and coworkers redesigned and rearranged the epothilone gene cluster according to the codon preferences of the $E$. coli host, and the engineered E. coli produced epothilones C and D; however, the yield was very low (Mutka et al., 2006). This approach may provide an alternate for the search of novel epothilone analogs. Bian et al. (2017) employed a newly established electroporation technique to insert the complete biosynthetic gene cluster of epothilone into Burkholderia K481B101. The results showed that the yield of epothilone increased by $\sim 75$-fold and reached $307 \mu \mathrm{g} / \mathrm{L}$ after optimization of the fermentation conditions and genetic modification of the host bacteria. The yield of epothilone reached $21.8 \mathrm{mg} / \mathrm{L}$ after the introduction of the whole biosynthetic gene cluster of epothilone in Myxococcus xanthus and optimization of the promoters (Yue et al., 2018). Heterologous expression of epothilone has achieved promising results, but so far, the purpose of largescale production of epothilone through heterologous expression has not been accomplished. Here are some possible reasons as follows. The research successfully expressed the active proteins of the epothilone gene cluster in E. coli without further optimizing the metabolic pathway. In addition, it is unknown whether the expressed proteins and products are toxic to the host. Therefore, the yield was very low in E. coli. In Burkholderia, despite optimization of the cultural conditions, introduction of the exogenous methylmalonyl-CoA biosynthetic pathway, and overexpression of rare tRNA genes, the epothilone yield has been improved. However, it is possible that Burkholderia does not produce abundant secondary metabolites, and thus lacks some endogenous and efficient elements for synthesizing PKS-NRPSs, resulting in a low expression yield in Burkholderia. Although the expression of epithilones in $M$. xanthus has obtained promising result, the transcription levels of epoP, epoC, and epoD were low in this experiment (Yue et al., 2018). Therefore, how to use metabolic regulation to stably and efficiently express the epothilone genes in M. xanthus may be a key issue for largescale production.

\section{Engineering and Heterologous Expression for Finding New Erythromycin}

Erythromycin was initially isolated from the fermentation products of Streptomyces erythraeus (synonymous to Saccharopolyspora erythraea; McGuire et al., 1952) and is a broad-spectrum macrolide antibiotic used to treat gram-positive bacterial infections. According to literature reports, the industrial production of erythromycin is mainly derived from the strains of S. erythraea spp. and its different genetic transformation lines, and the yield of erythromycin reaches 2.0-8.0 g/L (Minas et al., 1998; Karnicar et al., 2016). Increasing bacterial resistance promoted the development of second-generation erythromycin analogs (such as clarithromycin) and thirdgeneration erythromycin analogs (such as telithromycin) by modification and transformation of erythromycin. Erythromycin has a high economic value and considerable potential for new drug development.

The synthetic route of erythromycin contains two steps: polyketide skeleton formation and post-modification in Streptomyces (Rawlings, 2001). 6-Deoxyerythronolide B (6$\mathrm{dEB})$, a macrolide aglycone of erythromycin, is produced in six condensation steps, starting with propionyl-CoA and involving six reactions with methylmalonyl-CoA extender units catalyzed by deoxyerythronolide B synthase (DEBS), which includes the DEBS1, 2, and 3 enzymes (Donadio et al., 1991). Furthermore, 6-deoxyerythronolide B is consecutively converted to erythromycin D by EryF, EryB5, and EryC3. Erythromycin $\mathrm{D}$ is the first product with antibacterial activity, representing a branch in the biosynthetic pathway. Erythromycin D is converted by hydroxylase EryK to erythromycin C, which is then methylated by the methylase EryG to generate erythromycin A. Additionally, erythromycin D is converted to erythromycin B by methylation catalyzed by EryG, and erythromycin A is generated via a hydroxylation reaction catalyzed by EryK (Staunton and Wilkinson, 1997; Chen et al., 2008). These compounds are important initial precursors of erythromycin; thus, increasing the levels of propionyl CoA and methylmalonyl CoA are necessary to improve the yield of erythromycins. The Pfeifer group introduced the complete biosynthesis gene cluster of erythromycin in engineered $E$. coli to provide propionyl CoA and methylmalonyl CoA, thereby effectively increasing the yield of erythromycin. Moreover, a MatB-dependent pathway provided (2S)-methylmalonyl-CoA upon the addition of exogenous methylmalonate, which streamlined the routes responsible for the production of two starting erythromycin substrates to eventually produce a novel benzyl-erythromycin analog (Pfeifer et al., 2001; Jiang and Pfeifer, 2013). At present, it has a big advantage to achieve a new type of erythromycin by modifying the erythromycin biosynthetic gene cluster and its heterologous expression, which will also be an important field of drug research in synthetic biology.

\section{PRODUCTION SYSTEMS FOR SYNTHETIC BIOLOGY}

The development of synthetic biology has enabled the use of various systems to express heterologous genes. This technology has become an important approach for the production of target drugs. New clinical studies have shown that natural product drugs have a wide range of applications in the treatment of various diseases. An efficient expression system is required to meet the demands for various recombinant drugs. Currently, there is a lack of a universal chassis for heterologous expression of various types of metabolites. Commonly utilized microbial expression systems mainly include the E. coli, B. subtilis, yeast, and filamentous fungal expression systems. The former two systems are the most widely used prokaryotic host bacteria, and the latter two systems are generally used for eukaryotic expression. Understanding the biosynthetic mechanism allows rational selection and utilization of these 
expression systems for the expression of biosynthetic gene clusters for secondary metabolites.

\section{Prokaryotic Expression Systems}

Escherichia coli is a preferred microorganism for the production of recombinant proteins. E. coli is mainly used for cloning, genetic modification, and small-scale production, and the mechanisms of these processes have been thoroughly studied. $E$. coli has been widely used in the studies of heterologous medicinal proteins because of its clearly defined genetic background, fast reproduction, low cost, high expression level, stable ${ }^{2} \mathrm{H} /{ }^{13} \mathrm{C} /{ }^{15} \mathrm{~N}$ isotope labeling technology, and wide range of applications (Nuc and Nuc, 2006). However, as a prokaryote, E. coli has no regulatory mechanism for eukaryotic gene expression and it lacks the ability to catalyze posttranslational modifications (PTMs), especially modifications catalyzed by cytochrome P450 enzymes, which severely limits its application as a recombinant drug factory. PTMs play important roles in the folding, processing, stability, glycosylation, final biological activity, and immunogenicity of the proteins. A previous study has shown that transfer of the N-linked glycosylation system of Campylobacter jejuni to E. coli may produce glycosylated proteins (Wacker et al., 2002). Deficiency of the E. coli expression system for pharmaceutical protein production was overcome by a series of optimization strategies, such as codon optimization (BurgessBrown et al., 2008), vector construction (Hayashi and Kojima, 2008), development of a new secretion system to reduce inclusion body formation (Cheng et al., 2017), and self-induction (Briand et al., 2016), to optimize the expression of heterologous proteins in E. coli and to determine the best strategy.

Bacillus subtilis is an alternate host for the expression and secretion of heterologous proteins in some cases. Comparison with $E$. coli indicates that $B$. subtilis has strong protein secretion ability and does not easily form inclusion bodies. Moreover, $B$. subtilis is not pathogenic and has been used as a cell factory for producing enzymes, vitamins, and functional sugars in the expression systems for over a decade (van Dijl and Hecker, 2013). B. subtilis was engineered as a new expression system through the deletion of $36 \%$ of its genome, which did not affect cell growth or replication (Reuss et al., 2017). However, B. subtilis has certain disadvantages, including unstable vectors and protease secretion. To improve the application of this microbe, target genes were integrated into the host chromosome for expression, and a modular integration plasmid kit was developed (Phuong et al., 2012; Radeck et al., 2013). This approach was clearly successful in B. subtilis because the development of a promising $B$. subtilis expression system improved three aspects, such as large-scale genome reduction, elimination of carbon catabolite repression for multiple carbon source coutilization, and cell module engineering for specific product synthesis (Liu et al., 2019).

\section{Yeast Expression Systems}

Yeast is the simplest eukaryotic organism and is thus more suitable than prokaryotes for the expression of active eukaryotic proteins and can accomplish posttranslational modifications, including proteolysis of signal peptides, formation of disulfide bonds, and glycosylation. In particular, yeast is more suitable for gene expression of eukaryotic cytochrome oxidoreductases. S. cerevisiae has clear advantages in physiological characteristics related to industrial ethanol production, such as tolerance to $\mathrm{pH}$, high concentrations of ethanol, high sugar content, and high osmotic pressure (Baghban et al., 2019). Currently, many products in the market are produced by using $S$. cerevisiae, including artemisinic acid (Paddon et al., 2013), taxadiene (Engels et al., 2008), noscapine (Li and Smolke, 2016), ginsenoside compound $\mathrm{K}$ (Yan et al., 2014), and various types of vaccines (Nielsen, 2013). However, due to low protein yield, high glycosylation of glycoproteins, plasmid instability, and limited amounts of building blocks, the application of commercial products of S. cerevisiae is limited. Yarrowia lipolytica, a nonconventional yeast, has been extensively investigated and was considered a potential host for the production of natural products (Ma et al., 2020; Muhammad et al., 2020). This yeast has several advantages as an industrial host, including the ability to grow normally on low-cost substrates (e.g., sugars, lignocellulose, fatty acids, fats, waste oils, and crude glycerol) and under high-stress conditions (organic acids, hypersalinity, and metal stresses). Moreover, Y. lipolytica efficiently produces key structural building precursors (acetyl-CoA and malonyl$\mathrm{CoA}$ ), which are the main carbon sources for terpenoids and polyketides. Moreover, Y. lipolytica genes contain more introns than the genes of S. cerevisiae ( $\sim 15$ and $4 \%$, respectively), and this yeast has all the known types of alternative splicing (Mekouar et al., 2010), suggesting possible roles for regulated gene expression and/or generation of additional proteome complexity in Y. lipolytica. Most intron genes in yeast are not necessary for growth; however, a recent study demonstrated that introns in the yeast genome are independent of the host genes and can promote cell survival under starvation conditions, which may provide new ideas for the construction of new yeast expression systems to increase the production of heterologous proteins (Parenteau et al., 2019).

\section{Filamentous Fungal Expression Systems}

Heterologous expression of a large fragment of the secondary metabolite biosynthetic gene cluster has been performed mainly in the yeast $S$. cerevisiae and in the filamentous fungi Aspergillus oryzae and Aspergillus nidulans. Filamentous fungi have a very strong ability to express and secrete recombinant proteins and have posttranslational processing functions, such as glycosylation, cleavage by proteases, and the formation of disulfide bonds in heterologous proteins (Meyer, 2008). Many fungal hosts utilized for heterologous expression, such as $A$. niger and A. oryzae, are safe and have been employed in the food and food processing industries for a long time; these species have some clear advantages. First, those fungal hosts can express a complete gene cluster of natural fungal product biosynthesis, and the introns can be correctly spliced in the gene cluster; thus, intron removal is not required (Lazarus et al., 2014; Ma et al., 2016; He et al., 2018). Moreover, filamentous fungi can produce target products at low cost. For example, a high yield of multiactive enniatin can be obtained through heterologous expression in filamentous fungi. The 
TABLE 1 | Important progresses of selection of examples.

\begin{tabular}{|c|c|c|c|c|}
\hline Targets & Host & Products & Yield & References \\
\hline \multirow[t]{5}{*}{ Artemisinin } & S. cerevisiae & Artemisinic acid & 100 mg/L & Ro et al., 2006 \\
\hline & S. cerevisiae & Amorpha-4,11-diene & $40 \mathrm{~g} / \mathrm{L}$ & Westfall et al., 2012 \\
\hline & S. cerevisiae & Artemisinic acid & $25 \mathrm{~g} / \mathrm{L}$ & Paddon et al., 2013 \\
\hline & N. tabacum & Artemisinin & $6.8 \mu \mathrm{g} / \mathrm{g}$ dry weight & Farhi et al., 2011a \\
\hline & N. tabacum & Artemisinin & $0.8 \mathrm{mg} / \mathrm{g}$ dry weight & Malhotra et al., 2016 \\
\hline \multirow[t]{4}{*}{ Paclitaxel } & S. cerevisiae & Taxa-4(5),11(12)-diene & $8.7 \pm 0.85 \mathrm{mg} / \mathrm{L}$ & Engels et al., 2008 \\
\hline & E. coli & Taxa-4(5),11(12)-diene & $1.02 \pm 0.08 \mathrm{~g} / \mathrm{L}$ & Ajikumar et al., 2010 \\
\hline & co-culture of yeast and E. coli & Taxadien- $5 \alpha$-acetate-10 $\beta$-ol & $1 \mathrm{mg} / \mathrm{L}$ & Zhou et al., 2015 \\
\hline & N. tabacum & Taxadiene-5 $\alpha$-ol & $1.3 \mu \mathrm{g} / \mathrm{g}$ fresh weight & Li et al., 2019 \\
\hline \multirow[t]{2}{*}{ Tanshinone } & S. cerevisiae & Miltiradiene & 365 mg/L & Zhou et al., 2012 \\
\hline & S. cerevisiae & Miltiradiene & $3.5 \mathrm{~g} / \mathrm{L}$ & Hu et al., 2020 \\
\hline Breviscapine & S. cerevisiae & Scutellarin & 108 mg/L & Liu et al., 2018 \\
\hline Thebaine & S. cerevisiae & Thebaine & $6.4 \pm 0.3 \mu \mathrm{g} / \mathrm{L}$ & Galanie et al., 2015 \\
\hline Noscapine & S. cerevisiae & Noscapine & $2.2 \mathrm{mg} / \mathrm{L}$ & Li et al., 2018 \\
\hline Etoposide & N. tabacum & Deoxypodophyllotoxin & 4.3 mg/g dry weight & Schultz et al., 2019 \\
\hline \multirow[t]{2}{*}{ Epothilone } & Burkholderia K481-B101 & Epothilone & $307 \mu \mathrm{g} / \mathrm{L}$ & Bian et al., 2017 \\
\hline & M. xanthus & Epothilone & $21.8 \mathrm{mg} / \mathrm{L}$ & Yue et al., 2018 \\
\hline Erythromycin & E. coli & Novel benzyl-erythromycin & - & Jiang and Pfeifer, 2013 \\
\hline
\end{tabular}

nonribosomal polypeptide synthetase gene esyn1 encoding a nonribosomal peptide synthetase for enniatin from Fusarium oxysporum was expressed in A. niger under the control of the tunable bacterial-fungal hybrid promoter Tet-On. Optimized bioreactor cultivation of $A$. niger, engineered to include strong inducible Tet-On system, produced $\sim 5 \mathrm{~g} / \mathrm{L}$ enniatin (Meyer et al., 2015). At present, the primary disadvantage of the use of filamentous fungi as expression systems is that most fungi grow into cotton-like hyphal clusters under immersion conditions; these clusters are large spheres that can adhere to the surface of a fermenter and hinder the transfer of the substances and oxygen (Madhavan et al., 2017). On the other hand, filamentous fungi have considerable potential to secrete proteins due to higher number of hyphal branches and hyphal tips (Biesebeke et al., 2005). Long-term applications of filamentous fungi have been developed into a variety of efficient expression systems by means of genetic modification, mutagenesis, and culture optimization. Reasonable use of these promising expression systems may provide an excellent platform for research on biosynthetic pathways of natural products and heterologous expression.

In general, E. coli, yeast, and filamentous fungi are used primarily as expression systems. A suitable alternative microbial expression system with similar source genes may be preferentially selected for the production of some post-translationally modified proteins and membrane-bound proteins. For example, the P450 pathway of Streptomyces may be selected for expression in Streptomyces; the fungal P450 pathway may be selected for expression in filamentous fungi; and the plant $\mathrm{P} 450$ pathway may be generally selected for expression in yeast. The P450 enzymes of most eukaryotes are membrane bound, and most of them are located in the endoplasmic reticulum. The N-terminal region of these P450 enzymes contain a transmembrane helix responsible for the anchoring. However, modification at the $\mathrm{N}$-terminus of a plant P450 enzyme enables normal expression in E. coli to obtain soluble active protein ( $\mathrm{Zi}$ and Peters, 2013). The N-terminal anchor is less obstructive in the expression of P450 enzymes in yeast because the yeast intracellular environment is similar to that of plant cells and is more conducive to the expression of plant-derived P450 enzymes. Therefore, S. cerevisiae is a highly potent microbial cell factory and a commonly utilized host for the heterologous expression of P450 enzymes.

In addition, the increasing understanding of compartmentalized biosynthesis has promoted the development of compartmentalized engineering to synergize metabolic engineering and enzyme engineering (Heinig et al., 2013; Du and Li, 2021). Compartmental engineering of natural product biosynthetic pathways by changing the subcellular localization of related enzymes has been proven to be an effective strategy for elucidating the biosynthetic mechanism and increasing the titer of the target product. Through the regulation of the metabolic pathways of the compartments, each compartment has a unique physical and chemical environment, which provides favorable conditions for different metabolic pathways; while in subcellular compartments, the local concentration of substrates and enzymes in metabolic pathways may increase, resulting in faster catalytic efficiency (Farhi et al., 2011b); finally, it may be possible to solve the toxicity problem of certain heterologous proteins and metabolites through subcellular compartmentalization (Grewal et al., 2021). Thus, yeast has become a model system for compartmentalization engineering due to the abundant knowledge and genetic tools for manipulating the subcellular localization of enzymes.

\section{CONCLUSIONS}

From the limited selection of examples (Table 1), it is obvious that research on the synthetic biology of natural drugs is developing at a rapid and accelerating pace. Research and 
technological progress in this new field can provide the necessary foundation for the economic viability of the biotechnology industry. It can also be seen from the previous discussion that we have not fully achieved this and there are still many challenges to be solved. For plant natural products, incomplete understanding of biosynthetic pathways is one of the main obstacles preventing pathway reconstruction. For natural products that have reconstructed biosynthetic approach, the yields cannot meet the conditions for large-scale production due to the lack of the knowledge of multienzyme interaction, compartmentalization, or metabolic regulation. In addition, we need to optimize more general hosts to rapidly scale-up the production level of target drugs. If it continues to develop at the current rate, the synthetic biology of natural drugs will quickly move toward mass production and the market.

\section{REFERENCES}

Abdin, M. Z., and Alam, P. (2015). Genetic engineering of artemisinin biosynthesis: prospects to improve its production. Acta Physiol. Plant 37:33. doi: 10.1007/s11738-015-1771-5

Ajikumar, P. K., Xiao, W. H., Tyo, K. E. J., Wang, Y., Simeon, F., Leonard, E., et al. (2010). Isoprenoid pathway optimization for taxol precursor overproduction in Escherichia coli. Science 330, 70-74. doi: 10.1126/science.11 91652

Baghban, R., Farajnia, S., Rajabibazl, M., Ghasemi, Y., Mafi, A., Hoseinpoor, R., et al. (2019). Yeast expression systems: overview and recent advances. Mol. Biotechnol. 61, 365-384. doi: 10.1007/s12033-019-00164-8

Banek, K., Lalani, M., Staedke, S. G., and Chandramohan, D. (2014). Adherence to artemisinin-based combination therapy for the treatment of malaria: a systematic review of the evidence. Malar. J. 13:7. doi: 10.1186/1475-287 5-13-7

Beaudoin, G. A. W., and Facchini, P. J. (2014). Benzylisoquinoline alkaloid biosynthesis in opium poppy. Planta 240, 19-32. doi: 10.1007/s00425-014-2056-8

Bernardini, S., Tiezzi, A., Masci, V. L., and Ovidi, E. (2018). Natural products for human health: an historical overview of the drug discovery approaches. Nat. Prod. Res. 32, 1926-1950. doi: 10.1080/14786419.2017.13 56838

Bharati, A., Kar, M., and Sabat, S. C. (2012). Artemisinin inhibits chloroplast electron transport activity: mode of action. PLoS ONE 7:e38942. doi: 10.1371/journal.pone.0038942

Bian, X. Y., Tang, B., Yu, Y. C., Tu, Q., Gross, F., Wang, H. L., et al. (2017). Heterologous production and yield improvement of epothilones in Burkholderiales Strain DSM 7029. ACS Chem. Biol. 12, 1805-1812. doi: 10.1021/acschembio.7b00097

Biesebeke, R. T., Record, E., van Biezen, N., Heerikhuisen, M., Franken, A., Punt, P. J., et al. (2005). Branching mutants of Aspergillus oryzae with improved amylase and protease production on solid substrates. Appl. Microbiol. Biot. 69, 44-50. doi: 10.1007/s00253-005-1968-4

Briand, L., Marcion, G., Kriznik, A., Heydel, J. M., Artur, Y., Garrido, C., et al. (2016). A self-inducible heterologous protein expression system in Escherichia coli. Sci. Rep. 6:33037. doi: 10.1038/srep 33037

Brown, G. D. (2010). The Biosynthesis of artemisinin (Qinghaosu) and the phytochemistry of Artemisia annua L. (Qinghao). Molecules 15, 7603-7698. doi: 10.3390/molecules15117603

Brown, G. D., and Sy, L. K. (2004). In vivo transformations of dihydroartemisinic acid in Artemisia annua plants. Tetrahedron 60, 1139-1159. doi: 10.1016/j.tet.2003.11.070

Bryant, L., Flatley, B., Patole, C., Brown, G. D., and Cramer, R. (2015). Proteomic analysis of Artemisia annua - towards elucidating the biosynthetic

\section{AUTHOR CONTRIBUTIONS}

C-QL and P-JZ wrote the main part of the manuscript. $\mathrm{H}-\mathrm{ML}$, Q-YH, and G-HL made significant contributions and particularly in revising the manuscript. C-QL, G-HL, and P-JZ prepared and formatted the references. All authors contributed to the manuscript and approved the submitted version.

\section{FUNDING}

This research was funded by the National Natural Science Foundation of China (31970060, 31760018, and 31860015) and the Applied Basic Research Foundation of Yunnan Province (2018FA006 and 202001BB050061).

pathways of the antimalarial pro-drug artemisinin. Bmc Plant Biol. 15:175. doi: 10.1186/s12870-015-0565-7

Burgess-Brown, N. A., Sharma, S., Sobott, F., Loenarz, C., Oppermann, U., and Gileadi, O. (2008). Codon optimization can improve expression of human genes in Escherichia coli: a multi-gene study. Protein Expr. Purif. 59, 94-102. doi: 10.1016/j.pep.2008.01.008

Castro-Alvarez, A., Pineda, O., and Vilarrasa, J. (2018). Further insight into the interactions of the cytotoxic macrolides laulimalide and peloruside a with their common binding site. ACS Omega 3, 1770-1782. doi: 10.1021/acsomega.7b01723

Chang, Y., Wang, M., Li, J., and Lu, S. (2019). Transcriptomic analysis reveals potential genes involved in tanshinone biosynthesis in Salvia miltiorrhiza. Sci. Rep. 9:14929. doi: 10.1038/s41598-019-51535-9

Chen, X., Dang, T. T. T., and Facchini, P. J. (2015). Noscapine comes of age. Phytochemistry 111, 7-13. doi: 10.1016/j.phytochem.2014. 09.008

Chen, X., Hagel, J. M., Chang, L. M., Tucker, J. E., Shiigi, S. A., Yelpaala, Y., et al. (2018). A pathogenesis-related 10 protein catalyzes the final step in thebaine biosynthesis. Nat. Chem. Biol. 14, 738-743. doi: 10.1038/s41589-0180059-7

Chen, Y., Deng, W., Wu, J. Q., Qian, J. C., Chu, J., Zhuang, Y. P., et al. (2008). Genetic modulation of the overexpression of tailoring genes eryK and eryG leading to the improvement of erythromycin a purity and production in Saccharopolyspora erythraea fermentation. Appl. Environ. Microbiol. 74, 1820-1828. doi: 10.1128/AEM.02770-07

Cheng, C., Wu, S. S., Cui, L. P., Wu, Y. L., Jiang, T. Y., and He, B. F. (2017). A novel Ffu fusion system for secretory expression of heterologous proteins in Escherichia coli. Microb. Cell. Fact. 16:231. doi: 10.1186/s12934-0170845-z

Chevrette, M. G., Gutierrez-Garcia, K., Selem-Mojica, N., Aguilar-Martinez, C., Yanez-Olvera, A., Ramos-Aboites, H. E., et al. (2019). Evolutionary dynamics of natural product biosynthesis in bacteria. Nat. Prod. Rep. 37, 566-599. doi: $10.1039 / \mathrm{C} 9 \mathrm{NP} 00048 \mathrm{H}$

Chledzik, S., Strawa, J., Matuszek, K., and Nazaruk, J. (2018). Pharmacological effects of scutellarin, an active component of genus Scutellaria and Erigeron: a systematic review. Am. J. Chin. Med. 46, 319-337. doi: 10.1142/S0192415X18500167

Cravens, A., Payne, J., and Smolke, C. D. (2019). Synthetic biology strategies for microbial biosynthesis of plant natural products. Nat. Commun. 10:2142. doi: 10.1038/s41467-019-09848-w

Croteau, R., Ketchum, R. E. B., Long, R. M., Kaspera, R., and Wildung, M. R. (2006). Taxol biosynthesis and molecular genetics. Phytochem. Rev. 5, 75-97. doi: 10.1007/s11101-005-3748-2

Dai, Z. B., Liu, Y., Huang, L. Q., and Zhang, X. L. (2012). Production of miltiradiene by metabolically engineered Saccharomyces cerevisiae. Biotechnol. Bioeng. 109, 2845-2853. doi: 10.1002/bit.24547 
Dang, T. T. T., and Facchini, P. J. (2012). Characterization of three Omethyltransferases involved in noscapine biosynthesis in opium poppy. Plant Physiol. 159, 618-631. doi: 10.1104/pp.112.194886

Davey, S. G. (2020). Engineering etoposide. Nat. Rev.Chem. 4, 63-63. doi: $10.1038 /$ s41570-020-0166-3

Donadio, S., Staver, M. J., Mcalpine, J. B., Swanson, S. J., and Katz, L. (1991). Modular organization of genes required for complex polyketide biosynthesis. Science 252, 675-679. doi: 10.1126/science.2024119

Du, L., and Li, S. (2021). Compartmentalized biosynthesis of fungal natural products. Curr. Opin. Biotechnol. 69, 128-135. doi: 10.1016/j.copbio.2020.12.006

Ehrenworth, A. M., and Peralta-Yahya, P. (2017). Accelerating the semisynthesis of alkaloid-based drugs through metabolic engineering. Nat. Chem. Biol. 13, 249-258. doi: 10.1038/nchembio. 2308

Engels, B., Dahm, P., and Jennewein, S. (2008). Metabolic engineering of taxadiene biosynthesis in yeast as a first step towards Taxol (Paclitaxel) production. Metab. Eng. 10, 201-206. doi: 10.1016/j.ymben.2008.03.001

Farhi, M., Marhevka, E., Ben-Ari, J., Algamas-Dimantov, A., Liang, Z. B., Zeevi, V., et al. (2011a). Generation of the potent anti-malarial drug artemisinin in tobacco. Nat. Biotechnol. 29, 1072-1074. doi: 10.1038/nbt.2054

Farhi, M., Marhevka, E., Masci, T., Marcos, E., Eyal, Y., Ovadis, M., et al. (2011b). Harnessing yeast subcellular compartments for the production of plant terpenoids. Metab. Eng. 13, 474-481. doi: 10.1016/j.ymben.2011.05.001

Fossati, E., Ekins, A., Narcross, L., Zhu, Y., Falgueyret, J.-P., Beaudoin, G. A. W., et al. (2014). Reconstitution of a 10-gene pathway for synthesis of the plant alkaloid dihydrosanguinarine in Saccharomyces cerevisiae. Nat. Commun. 5:3283. doi: $10.1038 /$ ncomms 4283

Frasch, H. J., Medema, M. H., Takano, E., and Breitling, R. (2013). Design-based re-engineering of biosynthetic gene clusters: plug-and-play in practice. Curr. Opin. Biotechnol. 24, 1144-1150. doi: 10.1016/j.copbio.2013.03.006

Fuentes, P., Zhou, F., Erban, A., Karcher, D., Kopka, J., and Bock, R. (2016). A new synthetic biology approach allows transfer of an entire metabolic pathway from a medicinal plant to a biomass crop. Elife 5:e13664. doi: $10.7554 /$ eLife.13664.020

Galanie, S., Thodey, K., Trenchard, I. J., Interrante, M. F., and Smolke, C. D. (2015). Synthetic biology complete biosynthesis of opioids in yeast. Science 349, 1095-1100. doi: 10.1126/science.aac9373

Gao, J. L., Chen, G., He, H. Q., Liu, C., Xiong, X. J., Li, J., et al. (2017). Therapeutic effects of breviscapine in cardiovascular diseases: a review. Front. Pharmacol. 8:289. doi: 10.3389/fphar.2017.00289

Gerth, K., Steinmetz, H., Hofle, G., and Reichenbach, H. (2000). Studies on the biosynthesis of epothilones: the biosynthetic origin of the carbon skeleton. J. Antibiot. 53, 1373-1377. doi: 10.7164/antibiotics.53.1373

Gnanasekaran, T., Karcher, D., Nielsen, A. Z., Martens, H. J., Ruf, S., Kroop, X., et al. (2016). Transfer of the cytochrome P450-dependent dhurrin pathway from Sorghum bicolor into Nicotiana tabacum chloroplasts for light-driven synthesis. J. Exp. Bot. 67, 2495-2506. doi: 10.1093/jxb/erw067

Grewal, P. S., Samson, J. A., Baker, J. J., Choi, B., and Dueber, J. E. (2021). Peroxisome compartmentalization of a toxic enzyme improves alkaloid production. Nat. Chem. Biol. 17, 96-103. doi: 10.1038/s41589-020-00668-4

Guo, J., Ma, X. H., Cai, Y., Ma, Y., Zhan, Z. L., Zhou, Y. J., et al. (2016). Cytochrome P450 promiscuity leads to a bifurcating biosynthetic pathway for tanshinones. New Phytol. 210, 525-534. doi: 10.1111/nph.13790

Guo, J., Zhou, Y. J. J., Hillwigc, M. L., Shen, Y., Yang, L., Wang, Y. J., et al. (2013). CYP76AH1 catalyzes turnover of miltiradiene in tanshinones biosynthesis and enables heterologous production of ferruginol in yeasts. Proc. Natl. Acad. Sci. U.S.A. 110, 12108-12113. doi: 10.1073/pnas.1218061110

Hande, K. R. (1998). Etoposide: four decades of development of a topoisomerase II inhibitor. Eur. J. Cancer 34, 1514-1521. doi: 10.1016/S0959-8049(98)00228-7

Hayashi, K., and Kojima, C. (2008). pCold-GST vector: a novel cold-shock vector containing GST tag for soluble protein production. Protein Expr. Purif. 62, 120-127. doi: 10.1016/j.pep.2008.07.007

He, Y., Wang, B., Chen, W. P., Cox, R. J., He, J. R., and Chen, F. S. (2018). Recent advances in reconstructing microbial secondary metabolites biosynthesis in Aspergillus spp. Biotechnol. Adv. 36, 739-783. doi: 10.1016/j.biotechadv.2018.02.001

Heinig, U., Gutensohn, M., Dudareva, N., and Aharoni, A. (2013). The challenges of cellular compartmentalization in plant metabolic engineering. Curr. Opin. Biotechnol. 24, 239-246. doi: 10.1016/j.copbio.2012. 11.006

Hirata, K., Poeaknapo, C., Schmidt, J., and Zenk, M. H. (2004). 1,2Dehydroreticuline synthase, the branch point enzyme opening the morphinan biosynthetic pathway. Phytochemistry 65, 1039-1046. doi: 10.1016/j.phytochem.2004.02.015

Horwitz, S. B. (1994). How to make taxol from scratch. Nature 367, 593-594. doi: $10.1038 / 367593 \mathrm{a} 0$

Howat, S., Park, B., Oh, I. S., Jin, Y.-W., Lee, E.-K., and Loake, G. J. (2014). Paclitaxel: biosynthesis, production and future prospects. New Biotechnol. 31, 242-245. doi: 10.1016/j.nbt.2014.02.010

Hu, T., Zhou, J., Tong, Y., Su, P., Li, X., Liu, Y., et al. (2020). Engineering chimeric diterpene synthases and isoprenoid biosynthetic pathways enables high-level production of miltiradiene in yeast. Metab. Eng. 60, 87-96. doi: 10.1016/j.ymben.2020.03.011

Huang, Q. L., Roessner, C. A., Croteau, R., and Scott, A. I. (2001). Engineering Escherichia coli for the synthesis of taxadiene, a key intermediate in the biosynthesis of taxol. Bioorg. Med. Chem. 9, 2237-2242. doi: 10.1016/S0968-0896(01)00072-4

Ikram, N. K. B. K., Kashkooli, A. B., Peramuna, A. V., van der Krol, A. R., Bouwmeester, H., and Simonsen, H. T. (2017). Stable production of the antimalarial drug artemisinin in the moss Physcomitrella patens. Front. Bioeng. Biotechnol. 5:47. doi: 10.3389/fbioe.2017.00047

Jennewein, S., and Croteau, R. (2001). Taxol: biosynthesis, molecular genetics, and biotechnological applications. Appl. Microbiol. Biotechnol. 57, 13-19. doi: $10.1007 / \mathrm{s} 002530100757$

Jennewein, S., Park, H., DeJong, J. M., Long, R. M., Bollon, A. P., and Croteau, R. B. (2005). Coexpression in yeast of Taxus cytochrome p450 reductase with cytochrorne P450 oxygenases involved in taxol biosynthesis. Biotechnol. Bioeng. 89, 588-598. doi: 10.1002/bit.20390

Jiang, M., and Pfeifer, B. A. (2013). Metabolic and pathway engineering to influence native and altered erythromycin production through E. coli. Metab. Eng. 19, 42-49. doi: 10.1016/j.ymben.2013.05.005

Jiang, N. H., Zhang, G. H., Zhang, J. J., Shu, L. P., Zhang, W., Long, G. Q., et al. (2014). Analysis of the transcriptome of erigeron breviscapus uncovers putative scutellarin and chlorogenic acids biosynthetic genes and genetic markers. PLoS ONE 9:e100357. doi: 10.1371/journal.pone.0100357

Karnicar, K., Drobnak, I., Petek, M., Magdevska, V., Horvat, J., Vidmar, R. et al. (2016). Integrated omics approaches provide strategies for rapid erythromycin yield increase in Saccharopolyspora erythraea. Microb. Cell Fact. 15:93. doi: 10.1186/s12934-016-0496-5

Karunanithi, P. S., and Zerbe, P. (2019). Terpene synthases as metabolic gatekeepers in the evolution of plant terpenoid chemical diversity. Front. Plant Sci. 10:1166. doi: 10.3389/fpls.2019.01166

Kim, M. K., Park, G. H., Eo, H. J., Song, H. M., Lee, J. W., Kwon, M. J., et al. (2015). Tanshinone I induces cyclin D1 proteasomal degradation in an ERK1/2 dependent way in human colorectal cancer cells. Fitoterapia 101, 162-168. doi: 10.1016/j.fitote.2015.01.010

Kistler, H. C., and Broz, K. (2015). Cellular compartmentalization of secondary metabolism. Front. Microbiol. 6:68. doi: 10.3389/fmicb.2015. 00068

Koeksal, M., Jin, Y., Coates, R. M., Croteau, R., and Christianson, D. W. (2011). Taxadiene synthase structure and evolution of modular architecture in terpene biosynthesis. Nature 469, 116-138. doi: 10.1038/nature09628

Lau, W., and Sattely, E. S. (2015). Six enzymes from mayapple that complete the biosynthetic pathway to the etoposide aglycone. Science 349, 1224-1228. doi: 10.1126/science.aac7202

Lazarus, C. M., Williams, K., and Bailey, A. M. (2014). Reconstructing fungal natural product biosynthetic pathways. Nat. Prod. Rep. 31, 1339-1347. doi: $10.1039 / \mathrm{C} 4 \mathrm{NP} 00084 \mathrm{~F}$

Lenz, R., and Zenk, M. H. (1995). Acetyl coenzyme A: salutaridinol-7-Oacetyltransferase from Papaver somniferum plant cell cultures - the enzyme catalyzing the formation of thebaine in morphine biosynthesis. J. Biol. Chem. 270, 31091-31096. doi: 10.1074/jbc.270.52.31091

Li, J. H., Mutanda, I., Wang, K. B., Yang, L., Wang, J. W., and Wang, Y. (2019). Chloroplastic metabolic engineering coupled with isoprenoid pool enhancement for committed taxanes biosynthesis in Nicotiana benthamiana. Nat. Commun. 10:4850. doi: 10.1038/s41467-019-12879-y 
Li, M. J., Schneider, K., Kristensen, M., Borodina, I., and Nielsen, J. (2016). Engineering yeast for high-level production of stilbenoid antioxidants. Sci. Rep. 6:36827. doi: $10.1038 /$ srep36827

Li, Y., Li, S., Thodey, K., Trenchard, I., Cravens, A., and Smolke, C. D. (2018). Complete biosynthesis of noscapine and halogenated alkaloids in yeast. Proc. Natl. Acad. Sci. U.S.A. 115, E3922-E3931. doi: 10.1073/pnas.1721469115

Li, Y., Zhang, G. J., and Pfeifer, B.A. (2015). "Current and emerging options for Taxol production," in Biotechnology of Isoprenoids. Advances in Biochemical Engineering/Biotechnology, Vol. 148, eds J. Schrader and J. Bohlmann (Cham: Springer), 405-425. doi: 10.1007/10_2014_292

Li, Y. R., and Smolke, C. D. (2016). Engineering biosynthesis of the anticancer alkaloid noscapine in yeast. Nat. Commun. 7:12137. doi: $10.1038 /$ ncomms12137

Liu, W. C., Gong, T., and Zhu, P. (2016). Advances in exploring alternative Taxol sources. RSC Adv. 6, 48800-48809. doi: 10.1039/C6RA06640B

Liu, X. N., Cheng, J., Zhang, G. H., Ding, W. T., Duan, L. J., Yang, J., et al. (2018). Engineering yeast for the production of breviscapine by genomic analysis and synthetic biology approaches. Nat. Commun. 9:448. doi: 10.1038/s41467-018-02883-z

Liu, Y. F., Liu, L., Li, J. H., Du, G. C., and Chen, J. (2019). Synthetic biology toolbox and chassis development in Bacillus subtilis. Trends Biotechnol. 37, 548-562. doi: 10.1016/j.tibtech.2018.10.005

Liu, Z. Q. (2012). Chemical insights into ginseng as a resource for natural antioxidants. Chem. Rev. 112, 3329-3355. doi: 10.1021/cr100174k

Lu, X., Shen, Q., Zhang, L., Zhang, F. Y., Jiang, W. M., Lv, Z. Y., et al. (2013). Promotion of artemisinin biosynthesis in transgenic Artemisia annua by overexpressing ADS, CYP71AV1 and CPR genes. Ind. Crop. Prod. 49, 380-385. doi: 10.1016/j.indcrop.2013.04.045

Lv, Z. Y., Zhang, F. Y., Pan, Q. F., Fu, X. Q., Jiang, W. M., Shen, Q., et al. (2016). Branch pathway blocking in Artemisia annua is a useful method for obtaining high yield artemisinin. Plant Cell Physiol. 57, 588-602. doi: $10.1093 / \mathrm{pcp} / \mathrm{pcw} 014$

Ma, D.-M., Wang, Z., Wang, L., Alejos-Gonzales, F., Sun, M.-A., and Xie, D.Y. (2015). A genome-wide scenario of terpene pathways in self-pollinated Artemisia annua. Mol. Plant. 8, 1580-1598. doi: 10.1016/j.molp.2015.07.004

Ma, J., Gu, Y., Marsafari, M., and Xu, P. (2020). Synthetic biology, systems biology, and metabolic engineering of Yarrowia lipolytica toward a sustainable biorefinery platform. J. Ind. Microbiol. Biotechnol. 47, 845-862. doi: 10.1007/s10295-020-02290-8

Ma, Z., Li, W., and Yin, W. (2016). Progress in heterologous expression of fungal natural products-A review. Acta Microbiol. Sin. 56, 429-440. doi: 10.13343/j.cnki.wsxb.20150428. Available online at: http://en.cnki.com.cn/ Article_en/CJFDTotal-WSXB201603010.htm

Madhavan, A., Pandey, A., and Sukumaran, R. K. (2017). Expression system for heterologous protein expression in the filamentous fungus Aspergillus unguis. Bioresour. Technol. 245, 1334-1342. doi: 10.1016/j.biortech.2017.05.140

Malhotra, K., Subramaniyan, M., Rawat, K., Kalamuddin, M., Qureshi, M. I., Malhotra, P., et al. (2016). Compartmentalized metabolic engineering for artemisinin biosynthesis and effective malaria treatment by oral delivery of plant cells. Mol. Plant 9, 1464-1477. doi: 10.1016/j.molp.2016.09.013

Marques, J. V., Kim, K. W., Lee, C., Costa, M. A., May, G. D., Crow, J. A., et al. (2013). Next generation sequencing in predicting gene function in podophyllotoxin biosynthesis. J. Biol. Chem. 288, 466-479. doi: $10.1074 /$ jbc.M112.400689

McGuire, J. M., Bunch, R. L., Anderson, R. C., Boaz, H. E., Flynn, E. H., Powell, H. M., et al. (1952). Ilotycin, a new antibiotic. Antibiot. Chemother. 2, 281-283.

Mekouar, M., Blanc-Lenfle, I., Ozanne, C., Da Silva, C., Cruaud, C., Wincker, P., et al. (2010). Detection and analysis of alternative splicing in Yarrowia lipolytica reveal structural constraints facilitating nonsense-mediated decay of intronretaining transcripts. Genome Biol. 11:R65. doi: 10.1186/gb-2010-11-6-r65

Meyer, V. (2008). Genetic engineering of filamentous fungi-progress, obstacles and future trends. Biotechnol. Adv. 26, 177-185. doi: 10.1016/j.biotechadv.2007.12.001

Meyer, V., Fiedler, M., Nitsche, B., and King, R. (2015). "The cell factory Aspergillus enters the big data Era: opportunities and challenges for optimising product formation," in Filaments in Bioprocesses. Advances in Biochemical Engineering/Biotechnology, Vol. 149, eds R. Krull and T. Bley (Cham: Springer), 91-132. doi: 10.1007/10_2014_297
Minas, W., Brunker, P., Kallio, P. T., and Bailey, J. E. (1998). Improved erythromycin production in a genetically engineered industrial strain of Saccharopolyspora erythraea. Biotechnol. Prog. 14, 561-566. doi: 10.1021/bp980055t

Mizutani, M., and Sato, F. (2011). Unusual P450 reactions in plant secondary metabolism. Arch. Biochem. Biophys. 507, 194-203. doi: 10.1016/j.abb.2010.09.026

Morrison, K. C., and Hergenrother, P. J. (2014). Natural products as starting points for the synthesis of complex and diverse compounds. Nat. Prod. Rep. 31, 6-14. doi: 10.1039/C3NP70063A

Moses, T., Mehrshahi, P., Smith, A. G., and Goossens, A. (2017). Synthetic biology approaches for the production of plant metabolites in unicellular organisms. J. Exp. Bot. 68, 4057-4074. doi: 10.1093/jxb/erx119

Muhammad, A., Feng, X. D., Rasool, A., Sun, W. T., and Li, C. (2020). Production of plant natural products through engineered Yarrowia lipolytica. Biotechnol. Adv. 43:107555. doi: 10.1016/j.biotechadv.2020.1 07555

Munagala, R., Aqil, F., Jeyabalan, J., and Gupta, R. C. (2015). Tanshinone IIA inhibits viral oncogene expression leading to apoptosis and inhibition of cervical cancer. Cancer Lett. 356, 536-546. doi: 10.1016/j.canlet.2014. 09.037

Mutka, S. C., Carney, J. R., Liu, Y. Q., and Kennedy, J. (2006). Heterologous production of epothilone C and D in Escherichia coli. Biochemistry 45, 1321-1330. doi: 10.1021/bi052075r

Nabavi, S. M., Samec, D., Tomczyk, M., Milella, L., Russo, D., Habtemariam, S., et al. (2020). Flavonoid biosynthetic pathways in plants: versatile targets for metabolic engineering. Biotechnol. Adv. 38:107316. doi: 10.1016/j.biotechadv.2018.11.005

Newman, D. J., and Cragg, G. M. (2012). Natural products as sources of new drugs over the 30 years from 1981 to 2010. J. Nat. Prod. 75, 311-335. doi: $10.1021 / \mathrm{np} 200906 \mathrm{~s}$

Newman, D. J., and Cragg, G. M. (2020). Natural products as sources of new drugs over the nearly four decades from 01/1981 to 09/2019. J. Nat. Prod. 83, 770-803. doi: 10.1021/acs.jnatprod.9b01285

Nguyen, K. T., Arsenault, P. R., and Weathers, P. J. (2011). Trichomes plus roots plus $\mathrm{ROS}=$ artemisinin: regulating artemisinin biosynthesis in Artemisia annua L. In Vitro Cell. Dev. Biol. Plant 47, 329-338. doi: 10.1007/s11627-011-9343-x

Nielsen, J. (2013). Production of biopharmaceutical proteins by yeast advances through metabolic engineering. Bioengineered 4, 207-211. doi: 10.4161/bioe. 22856

Nielsen, J., and Keasling, J. D. (2011). Synergies between synthetic biology and metabolic engineering. Nat. Biotechnol. 29, 693-695. doi: 10.1038/nb t.1937

Nuc, P., and Nuc, K. (2006). Recombinant protein production in Escherichia coli. Postepy Biochem. 52, 448-456. Available online at: https://www. researchgate.net/publication/267979999_Recombinant_protein_production_ in_Escherichia_coli

Olsson, M. E., Olofsson, L. M., Lindahl, A. L., Lundgren, A., Brodelius, M., and Brodelius, P. E. (2009). Localization of enzymes of artemisinin biosynthesis to the apical cells of glandular secretory trichomes of Artemisia annua L. Phytochemistry 70, 1123-1128. doi: 10.1016/j.phytochem.2009. 07.009

Onoyovwe, A., Hagel, J. M., Chen, X., Khan, M. F., Schriemer, D. C., and Facchini, P. J. (2013). Morphine biosynthesis in opium poppy involves two cell types: sieve elements and laticifers. Plant Cell 25, 4110-4122. doi: 10.1105/tpc.113.115113

Paddon, C. J., Westfall, P. J., Pitera, D. J., Benjamin, K., Fisher, K., McPhee, D., et al. (2013). High-level semi-synthetic production of the potent antimalarial artemisinin. Nature 496, 528-532. doi: 10.1038/nature 12051

Pandey, R. P., Parajuli, P., Koffas, M. A. G., and Sohng, J. K. (2016). Microbial production of natural and non-natural flavonoids: pathway engineering, directed evolution and systems/synthetic biology. Biotechnol. Adv. 34, 634-662. doi: 10.1016/j.biotechadv.2016.02.012

Parenteau, J., Maignon, L., Berthoumieux, M., Catala, M., Gagnon, V., and Abou Elela, S. (2019). Introns are mediators of cell response to starvation. Nature 565, 612-617. doi: 10.1038/s41586-018-0859-7 
Pfeifer, B. A., Admiraal, S. J., Gramajo, H., Cane, D. E., and Khosla, C. (2001). Biosynthesis of complex polyketides in a metabolically engineered strain of E. coli. Science 291, 1790-1792. doi: 10.1126/science.10 58092

Phuong, N. D., Jeong, Y. S., Selvaraj, T., Kim, S. K., Kim, Y. H., Jung, K. H., et al. (2012). Production of XynX, a large multimodular protein of Clostridium thermocellum, by protease-deficient Bacillus subtilis Strains. Appl. Biochem. Biotechnol. 168, 375-382. doi: 10.1007/s12010-012-9781-x

Presley, C. C., and Lindsley, C. W. (2018). DARK classics in chemical neuroscience: opium, a historical perspective. ACS Chem. Neurosci. 9, 2503-2518. doi: 10.1021/acschemneuro.8b00459

Prince, M. J., Wu, F., Guo, Y. F., Robledo, L. M. G., O’Donnell, M., Sullivan, R., et al. (2015). The burden of disease in older people and implications for health policy and practice. Lancet 385, 549-562. doi: 10.1016/S0140-6736(14)6 1347-7

Radeck, J., Kraft, K., Bartels, J., Cikovic, T., Durr, F., Emenegger, J., et al. (2013). The Bacillus BioBrick Box: generation and evaluation of essential genetic building blocks for standardized work with Bacillus subtilis. J. Biol. Eng. 7:29. doi: 10.1186/1754-1611-7-29

Rawlings, B. J. (2001). Type I polyketide biosynthesis in bacteria (Part B). Nat. Prod. Rep. 18, 231-281. doi: 10.1039/b100191o

Reuss, D. R., Altenbuchner, J., Mader, U., Rath, H., Ischebeck, T., Sappa, P. K., et al. (2017). Large-scale reduction of the Bacillus subtilis genome: consequences for the transcriptional network, resource allocation, and metabolism. Genome Res. 27, 289-299. doi: 10.1101/gr.215293.116

Rida, P. C. G., LiVecche, D., Ogden, A., Zhou, J., and Aneja, R. (2015). The noscapine chronicle: a pharmaco-historic biography of the opiate alkaloid family and its clinical applications. Med. Res. Rev. 35, 1072-1096. doi: $10.1002 /$ med.21357

Ro, D. K., Paradise, E. M., Ouellet, M., Fisher, K. J., Newman, K. L., Ndungu, J. M., et al. (2006). Production of the antimalarial drug precursor artemisinic acid in engineered yeast. Nature 440, 940-943. doi: 10.1038/nature 04640

Roze, L. V., Chanda, A., and Linz, J. E. (2011). Compartmentalization and molecular traffic in secondary metabolism: a new understanding of established cellular processes. Fungal Genet. Biol. 48, 35-48. doi: 10.1016/j.fgb.2010. 05.006

Schoendorf, A., Rithner, C. D., Williams, R. M., and Croteau, R. B. (2001). Molecular cloning of a cytochrome P450 taxane 10 ?-hydroxylase cDNA from Taxus and functional expression in yeast. Proc. Natl. Acad. Sci. U.S.A. 98, 1501-1506. doi: 10.1073/pnas.98.4.1501

Schultz, B. J., Kim, S. Y., Lau, W., and Sattely, E. S. (2019). Total biosynthesis for milligram-scale production of etoposide intermediates in a plant chassis. J. Am. Chem. Soc. 141, 19231-19235. doi: 10.1021/jacs.9b 10717

Singh, A., Menendez-Perdomo, I. M., and Facchini, P. J. (2019). Benzylisoquinoline alkaloid biosynthesis in opium poppy: an update. Phytochem. Rev. 18, 1457-1482. doi: 10.1007/s11101-01909644-w

Sparano, J. A., Vrdoljak, E., Rixe, O., Xu, B. H., Manikhas, A., Medina, C., et al. (2010). Randomized phase III trial of ixabepilone plus capecitabine versus capecitabine in patients with metastatic breast cancer previously treated with an anthracycline and a taxane. J. Clin. Oncol. 28, 3256-3263. doi: 10.1200/JCO.2009.24.4244

Stahlhut, S. G., Siedler, S., Malla, S., Harrison, S. J., Maury, J., Neves, A. R., et al. (2015). Assembly of a novel biosynthetic pathway for production of the plant flavonoid fisetin in Escherichia coli. Metab. Eng. 31, 84-93. doi: 10.1016/j.ymben.2015.07.002

Staunton, J., and Wilkinson, B. (1997). Biosynthesis of erythromycin and rapamycin. Chem. Rev. 97, 2611-2629. doi: 10.1021/cr9 600316

Sy, L. K., and Brown, G. D. (2002). The mechanism of the spontaneous autoxidation of dihydroartemisinic acid. Tetrahedron 58, 897-908. doi: 10.1016/S0040-4020(01)01193-0

Tang, L., Shah, S., Chung, L., Carney, J., Katz, L., Khosla, C., et al. (2000). Cloning and heterologous expression of the epothilone gene cluster. Science 287, 640-642. doi: 10.1126/science.287.54 53.640
Tatsis, E. C., and O'Connor, S. E. (2016). New developments in engineering plant metabolic pathways. Curr. Opin. Biotechnol. 42, 126-132. doi: 10.1016/j.copbio.2016.04.012

Teponno, R. B., Kusari, S., and Spiteller, M. (2016). Recent advances in research on lignans and neolignans. Nat. Prod. Rep. 33, 1044-1092. doi: 10.1039/C6NP00021E

Thomas, E., Tabernero, J., Fornier, M., Conte, P., Fumoleau, P., Lluch, A., et al. (2007). Phase II clinical trial of ixabepilone (BMS-247550), an epothilone B analog, in patients with taxane-resistant metastatic breast cancer. J. Clin. Oncol. 25, 3399-3406. doi: 10.1200/JCO.2006.08.9102

Trenchard, I. J., and Smolke, C. D. (2015). Engineering strategies for the fermentative production of plant alkaloids in yeast. Metab. Eng. 30, 96-104. doi: 10.1016/j.ymben.2015.05.001

Tu, Y. (2011). The discovery of artemisinin (qinghaosu) and gifts from Chinese medicine. Nat. Med. 17, 1217-1220. doi: 10.1038/nm.2471

van Dijl, J. M., and Hecker, M. (2013). Bacillus subtilis: from soil bacterium to super-secreting cell factory. Microb. Cell. Fact. 12:3. doi: 10.1186/1475-2859-12-3

Wacker, M., Linton, D., Hitchen, P. G., Nita-Lazar, M., Haslam, S. M., North, S. J., et al. (2002). N-linked glycosylation in Campylobacter jejuni and its functional transfer into E. coli. Science 298, 1790-1793. doi: 10.1126/science.298.5599.1790

Wang, B., Kashkooli, A. B., Sallets, A., Ting, H. M., de Ruijter, N. C. A., Olofsson, L., et al. (2016). Transient production of artemisinin in Nicotiana benthamiana is boosted by a specific lipid transfer protein from A. annua. Metab. Eng. 38, 159-169. doi: 10.1016/j.ymben.2016.07.004

Wang, P. P., Yang, C. S., Li, X. D., Jiang, Y. G., Yan, X., and Zhou, Z. H. (2018). Route to artificially synthesize plant natural products. Chin. J. Org. Chem. 38, 2199-2214. doi: 10.6023/cjoc201805060

Weid, M., Ziegler, J., and Kutchan, T. M. (2004). The roles of latex and the vascular bundle in morphine biosynthesis in the opium poppy, Papaver somniferum. Proc. Natl. Acad. Sci. U.S.A. 101, 13957-13962. doi: 10.1073/pnas.0405704101

Westfall, P. J., Pitera, D. J., Lenihan, J. R., Eng, D., Woolard, F. X., Regentin, R., et al. (2012). Production of amorphadiene in yeast, and its conversion to dihydroartemisinic acid, precursor to the antimalarial agent artemisinin. Proc. Natl. Acad. Sci. U.S.A. 109, 111-118. doi: 10.1073/pnas.11107 40109

Winzer, T., Gazda, V., He, Z., Kaminski, F., Kern, M., Larson, T. R., et al. (2012). A Papaver somniferum 10-Gene cluster for synthesis of the anticancer alkaloid noscapine. Science 336, 1704-1708. doi: 10.1126/science.12 20757

Wu, W. Y., and Wang, Y. P. (2012). Pharmacological actions and therapeutic applications of Salvia miltiorrhiza depside salt and its active components. Acta Pharmacol. Sin. 33, 1119-1130. doi: 10.1038/aps.2012.126

Xu, J. P., Wei, K. H., Zhang, G. J., Lei, L. J., Yang, D. W., Wang, W. L., et al. (2018). Ethnopharmacology, phytochemistry, and pharmacology of Chinese Salvia species: a review. J. Ethnopharmacol. 225, 18-30. doi: 10.1016/j.jep.2018.06.029

$\mathrm{Xu}$, Z., Peters, R. J., Weirather, J., Luo, H., Liao, B., Zhang, X., et al. (2015). Full-length transcriptome sequences and splice variants obtained by a combination of sequencing platforms applied to different root tissues of Salvia miltiorrhiza and tanshinone biosynthesis. Plant J. 82, 951-961. doi: 10.1111/tpj. 12865

Yan, X., Fan, Y., Wei, W., Wang, P. P., Liu, Q. F., Wei, Y. J., et al. (2014). Production of bioactive ginsenoside compound $\mathrm{K}$ in metabolically engineered yeast. Cell Res. 24, 770-773. doi: 10.1038/cr.2014.28

Yoshikawa, M., Murakami, T., Ueno, T., Yashiro, K., Hirokawa, N., Murakami, N., et al. (1997). Bioactive saponins and glycosides. VIII. Notoginseng (1): new dammarane-type triterpene oligoglycosides, notoginsenosides-A, -B, -C, and D, from the dried root of Panax notoginseng (Burk.) F.H. Chen. Chem. Pharm. Bull. 45, 1039-1045. doi: 10.1248/cpb.45.1039

Yu, Q. X., Chen, H. L., Sheng, L. L., Liang, Y. M., and Li, Q. F. (2014). Sodium tanshinone IIA sulfonate prolongs the survival of skin allografts by inhibiting inflammatory cell infiltration and $\mathrm{T}$ cell proliferation. Int. Immunopharmacol. 22, 277-284. doi: 10.1016/j.intimp.2014.07.002

Yue, X. J., Cui, X. W., Zhang, Z., Hu, W. F., Li, Z. F., Zhang, Y. M., et al. (2018). Effects of transcriptional mode on promoter substitution and tandem engineering for the production of epothilones in Myxococcus xanthus. Appl. Microbiol. Biotechnol. 102, 5599-5610. doi: 10.1007/s00253-0189023-4 
Zhang, J. (2014). Medicinal value of anti-cancer plant Taxus Chinese. China Pharm. 23, 1-3. Available online at: http://en.cnki.com.cn/Article_en/ CJFDTotal-YYGZ201401001.htm

Zhou, K., Qiao, K. J., Edgar, S., and Stephanopoulos, G. (2015). Distributing a metabolic pathway among a microbial consortium enhances production of natural products. Nat. Biotechnol. 33, 377-383. doi: 10.1038/nbt.3095

Zhou, Y. J. J., Gao, W., Rong, Q. X., Jin, G. J., Chu, H. Y., Liu, W. J., et al. (2012). Modular pathway engineering of diterpenoid synthases and the mevalonic acid pathway for miltiradiene production. J. Am. Chem. Soc. 134, 3234-3241. doi: $10.1021 /$ ja2114486

Zi, J., and Peters, R. J. (2013). Characterization of CYP76AH4 clarifies phenolic diterpenoid biosynthesis in the Lamiaceae. Org. Biomol. Chem. 11, 7650-7652. doi: $10.1039 / \mathrm{c} 3 \mathrm{ob} 41885 \mathrm{e}$

Ziegler, J., Facchini, P. J., Geissler, R., Schmidt, J., Ammer, C., Kramell, R., et al. (2009). Evolution of morphine biosynthesis in opium poppy. Phytochemistry 70, 1696-1707. doi: 10.1016/j.phytochem.2009. 07.006
Conflict of Interest: The authors declare that the research was conducted in the absence of any commercial or financial relationships that could be construed as a potential conflict of interest.

Publisher's Note: All claims expressed in this article are solely those of the authors and do not necessarily represent those of their affiliated organizations, or those of the publisher, the editors and the reviewers. Any product that may be evaluated in this article, or claim that may be made by its manufacturer, is not guaranteed or endorsed by the publisher.

Copyright (c) $2021 \mathrm{Li}, \mathrm{Lei}, \mathrm{Hu}, \mathrm{Li}$ and Zhao. This is an open-access article distributed under the terms of the Creative Commons Attribution License (CC BY). The use, distribution or reproduction in other forums is permitted, provided the original author(s) and the copyright owner(s) are credited and that the original publication in this journal is cited, in accordance with accepted academic practice. No use, distribution or reproduction is permitted which does not comply with these terms. 